\title{
LA CRONOLOGÍA ABSOLUTA DE ANDALUCÍA OCCIDENTAL DURANTE LA PREHISTORIA RECIENTE (6100-850 A.C.)
}

\section{ABSOLUTE CHRONOLOGY OF WESTERN ANDALUSIA DURING THE RECENT PREHISTORY (6100-850 B.C.)}

\author{
por
}

ALFREDO MEDEROS MARTÍN*

RESUMEN El objetivo de este trabajo es presentar la cronología calibrada absoluta de la prehistoria reciente del Suroeste de la Península Ibérica, que incluye las provincias de Málaga, Córdoba, Sevilla, Cádiz y Huelva, con una discusión de sus contextos arqueológicos, aportando la secuencia cronológica provisional desde el Neolítico Inicial al comienzo de la colonización fenicia.

ABSTRACT The aim of this paper is display the absolute calendar chronology of the Late Prehistory in Western Andalusia, Málaga, Córdoba, Sevilla, Cádiz y Huelva, with a discussion of the archaeological evidence in each archaeological site, and attemps to establish a provisional chronological secuence between the Early Neolithic to the beginning of the phoenician colonization.

\section{INTRODUCCIÓN}

Tradicionalmente, dado el mayor esfuerzo de investigación en Andalucía Oriental, la importancia de la región occidental de esta Comunidad Autónoma ha quedado minimizada salvo para el Neolítico, con estudios particularmente concentrados en la provincia de Málaga, y el Bronce Final 3/III, con las posteriores etapas "orientalizantes", cuando quizás coexistiría la posible existencia de un Estado Tartésico recogido en fuentes clásicas tardías con las colonias fenicias en èl litoral andaluz y navegaciones griegas.

El objetivo de este trabajo serâ tratar de articular la secuencia de Andalucía Occidental entre el Neolítico y el Bronce Final, a partir de las dataciones de $\mathrm{C}^{14}$ publicadas y la discusión de los contextos' estratigráficos de los cuales proceden, que permita indentificar mejor las fases temporales que caracterizaron a esta región y contrastarlas con las que conocemos en Andalucía Oriental (Mederos e.p.).

* Becario Postdoctoral de la Dirección General de Investigación Científica y Técnica en el Department of Archaeology, University of Bristol, 11 Woodland Road, Bristol BS8·ITB, Tel.\& Fax: 44 117.928 88 77. E-mail: archaeology@bris.ac.uk 
En segundo lugar, se pretende introducir el uso de cronologías calibradas cuyo uso sigue sin generalizarse en la investigación sobre la prehistoria española. Para ello se presentan todas las dataciones tanto en su formato convencional como calibradas, de tal forma que se ayude al investigador a introducirse en esta nueva estructuración cronológica. Este formato permite, además, tener siempre ambos referentes ya que las dataciones calibradas a medida que van surgiendo nuevas versiones de los programas de calibración experimentan ligeras modificaciones al irse incorporando nuevas curvas de calibración que permiten ajustes en las que actualmente se conocen. No obstante, hasta que en el futuro no contemos con una curva de calibración concreta de un área muy próxima a la región de estudio, se seguirán produciendo ciertos ajustes.

\section{NEOLÍTICO}

\section{Málaga}

Cueva de Nerja (Nerja)

La Cueva de Nerja, uno de los yacimientos más importantes del Neolítico andaluz con la Cueva de la Carigüela (Piñar), pese a sus prometedores inicios con una monografía de M. Pellicer (1963), ha sido objeto de sucesivas campañas de excavación sin haber cumplido todas las expectativas en ella depositadas por falta de suficientes publicaciones.

Descubierta en 1959, se han realizado campañas de excavaciones en los años 1959 y 1960 por M. Pellicer; en 1962 por A.M. De la Quadra Salcedo. Entre 1965-1968 otras cinco campañas por F. Jorda y A. Arribas. Reanudación de los trabajos de M. Pellicer en 1979-80, 1982, 1984-87; y finalmente entre 1979-83 y 1985-86 nuevas actuaciones por $F$. Jordá.

La primera determinación radiocarbónica obtenida en la Cueva de Nerja (Hopf y Pellicer 1970: 25), GRN-5526 3115 \pm 40 a.C. (cal. 3932-3810 A.C.) procedente de un silo que contenía semillas de cebada, trigo, bellotas y Olea, perteneciente al Neolítico Final, jugó un papel determinante en el encuadre de este periodo cronológico, tan importante como para el Neolítico Medio supuso tres años después la serie de la Cueva de los Murciélagos.

La serie reciente que disponemos de la Cueva de Nerja para los estratos post-paleolíticos, excavados tanto por Pellicer como por Jordá, es la procedente de la campaña de 1979 de Pellicer en las Salas de la Mina (NM) y la Torca (NT) (Pellicer y Acosta 1986: 381-382; Pellicer 1987: 643). Ello lamentablemente resta precisión a las determinaciones puesto que fue la primera campaña de las nuevas excavaciones tras las actuaciones de 1960, lo que obviamente se ve reflejado en una menor precisión en algunos niveles identificados en contraste con campañas posteriores. Un dato positivo son dos posteriores dataciones de UGRA (González-Gómez et alii 1987: 385) procedentes de las campañas de 1980 y 1982.

El final del Epipaleolítico, en contacto con el Neolítico Antiguo (N.5-4) es datado por (NT) GaK-8962 6010 \pm 200 a.C. (cal. 6990-6770 A.C), (NM) GaK-8974 5940 \pm 170 a.C. (cal. 6650 A.C.), (NT) GaK-8963 $\mathbf{5 2 1 0} \pm 150$ a.C. (cal. 5980 A.C.) y (NT) GaK-8975 5180 \pm 150 a.C. (cal. 5970 A.C.) (Pellicer y Acosta 1982: 54). Inaceptable, según su excavador (Pellicer 1987: 643), sería (NT) GaK-8961 9620 320 a.C.

En el Neolítico Antiguo, en su segundo y último momento, N.9(N. 4 de 1979), (NT) UGRA-261 4250 \pm 100 a.C. (cal. 5210-5090 A.C.) (González-Gómez et alii 1987: 385).

Del contacto del Neolítico Antiguo y el Medio (N.4-3) se citan (Pellicer y Acosta 1986: 381-382; Pellicer 1987: 643), (NM) GaK-8973 5210 \pm 180 a.C. (cal. 5980 A.C.) sobre bellotas, y (NT) GaK-8959 4530 \pm 180 a.C. (cal. 5430 A.C.). 
En Neolítico Pleno (N.3), una datación rechazada (Pellicer 1987: 643), (NM) GaK-8972 7950 230 a.C.

En el Neolítico Pleno o Reciente, otra datación no admitida (Ib. 1987: 643) (NM) GaK-8971 5220 \pm 150 a.C. (cal. 5990 A.C.).

En la zona de contacto entre el Neolítico Reciente y Transición al Calcolítico (N.2-1), (NM) GaK-8969 3840 \pm 140 a.C. (cal. 4680-4620 A.C.) (Pellicer y Acosta 1982: 54) y otra rechazada (Pellicer 1987: 643), (NM) GaK-8970 6820 \pm 140 a.C.

En el estrato de Transición al Calcolítico (N.1) (NM) GaK-8968 5440 \pm 120 a.C. (cal. 6180 A.C.), no admitida (Ib. 1987: 643).

Del contacto de Transición al Calcolítico y Calcolítico Antiguo (N.3-2), (NT) GaK-8960 2860 210 a.C. (cal. 3630 A.C.), publicada inicialmente con diferente desviación estadística $2860 \pm 120$ a.C. (Acosta

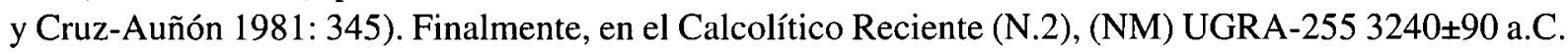
(cal. 3980 A.C.) (González-Gómez et alii 1987: 385), que resulta difícilmente admisible ya que señala un momento del Neolítico Final, cuando en teoría debería estar datando el Calcolítico Final.

La problemática inherente a estas dataciones la ponen en evidencia los propios autores (Pellicer y Acosta 1986: 403, fig. 2 y 1986: 380, lám. 6) cuando a la hora de seleccionar dataciones representativas sólo colocan dos de ellas, incorrectamente el 5440 a.C. (6180 A.C.) para el inicio del Neolítico Antiguo, pues conviene advertir que ésta era una datación procedente del nivel representativo de la Transición al Calcolítico; y 3840 a.C. (4680-4620 A.C.) para el inicio del Neolítico Reciente, que tampoco es su ubicación precisa pues proviene del nivel de contacto entre el Neolítico Reciente y el de Transición al Calcolítico, que en el cuadro está representado por un 3000 a.C.

Consecuentemente, los autores optan al final por una periodización a modo de "hipótesis de trabajo", Neolítico Antiguo 5500-5400 a.C., Neolítico Pleno 4500-3800 a.C., Neolítico Reciente 3800-3000 a.C., Transición al Calcolítico 3000-2800 a.C., Calcolítico Antiguo con aportaciones occidentales 2800-2300 a.C., y Calcolítico Reciente o Millares-Campaniforme 2300-1800 a.C., del que posteriormente han desgajado un Calcolítico Medio (Pellicer 1987: 329, fig. 3) e inicios del Bronce o Argar A.

Por nuestra parte, con la prudencia que deben tomarse cualquier afirmación ante semejante problemática, y tomando en consideración la secuencia artefactual y radiocarbónica, ese nivel de contacto entre Epipaleolítico y Neolítico Antiguo, lo consideramos una posible mezcla de materiales de la base del Neolítico Medio con el estrato epipaleolítico.

El denominado Neolítico Antiguo y Neolítico Medio formarían un sólo conjunto asignable a este último periodo, presentando obviamente los inicios del Neolítico Medio una mayor presencia de cerámicas impresas, cardiales entre otras. A este nivel adjudicaríamos las fechas del 4250 a.C. (5210-5090 A.C.) del laboratorio de Granada y 4530 a.C. (5430 A.C.) de Gakushuin, ésta última en la zona de contacto con el Neolítico Pleno de los excavadores y la única que acepta J. Bernabeu (1989: 145), mientras genéricamente J. Fortea y B. Martí (1984-85: 185-186) o J. Zilhão (1993: 46) prescinden de todas ellas.

Al Neolítico Final asignaríamos la clásica fecha del 3115 a.C. (3932-3810 A.C.) y 3840 a.C. (4680-4620 A.C.) también de Gakushuin, presente en el contacto del Neolítico Reciente con el de Transición al Calcolítico de los excavadores.

Resulta necesario insistir por último en lo conveniente que se realizasen nuevas datacionęs con muestras procedentes de las campañas entre 1980-87, de las que sólo disponemos dos de UGRA, que sirvan de contraste a la serie de $\mathrm{GaK}$, y asimismo de las resultantes de las excavaciones de Jordá entre 1979-86, de las cuales desconocemos ninguna fecha postpaleolítica publicada.

No obstante, E. Badal (Rodríguez Ariza 1992: 341, 343) cita dos determinaciones, una del $5290 \pm 80$ a.C. (6040 A.C.) asignable al Neolítico Inicial y otra del $4470 \pm 60$ a.C. (5330 A.C.) correspondiente al Neolítico Medio. Sin embargo al desconocer el laboratorio, tipo de muestra y contexto, resultan muy difíciles de valorar 
aunque la primera representaría un Neolítico Inicial, aún por publicar con claridad, más antiguo que las muestras de Cova de l'Or, aunque no sobrepasaría al $5590 \pm 140$ a.C. (6380 A.C.) que parece haberse obtenido en Cova de les Cendres.

\section{Cueva del Toro (Antequera)}

La Cueva del Toro está situada en la Sierra del Torcal, y en ella se han realizado campañas de excavación en los años 1977, 1980-81, 1985 y 1988 dirigidas por D. Martín-Socas y M $^{\mathrm{a}}$.D. Camalich. Cuenta con una de las estratigrafías más importantes de la región andaluza, y de ella proceden una serie de dataciones especialmente interesantes para el Neolítico Medio y Final documentado en el yacimiento, que permiten contrastar desde un medio continental, la Depresión de Antequera, el entorno costero de la Cueva de Nerja.

De la amplia serie disponible, ciñéndonos sólo a las publicadas, para el estrato IV, correspondiente al Neolítico Medio, cuenta con UGRA-194 4450 \pm 280 a.C. (cal. 5320 A.C.) (González-Gómez et alii 1987: 382) también publicada con diferente desviación estándar $4450 \pm 150$ a.C. (Meneses 1991:21), y GRN-15443 4370 \pm 70 a.C. (cal. 5260 A.C.) (González Quintero 1990: 119), las cuales se correlacionan bien con las de la Cueva de los Murciélagos de Zuheros.

Del estrato III, del Neolítico Final, subdividido internamente en IIIa y IIIb, GaK-8060 3500 \pm 120 a.C. (cal. 4330 A.C.), GaK-8059 3370 \pm 230 a.C. (cal. 4220-4110 A.C.) (Martín Socas et alii 1989: 2-5), ambas de la campaña de 1977, y GRN-15437 3250 \pm 60 a.C. (cal. 3990 A.C.) (González Quintero 1990:131).

Finalmente procedente del nivel II, pero de un área afectada por intrusiones superficiales, UGRA-189

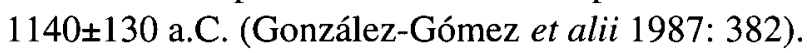

Cueva de las Palomas (Teba)

La Cueva de las Palomas, emplazada en la Sierra de Peñarrubia y a cuyo pie aflora el Nacimiento de Torrox que desemboca en el río de la Venta, fue objeto de una excavación furtiva por un grupo de aficionados en 1974-75, área que fue posteriormente afectada por nuevas remociones por cazadores de palomas. $A$ posteriori, se realizaron excavaciones dirigidas por J.E. Ferrer, I. Marques y A. de Luque en 1975, y con la incorporación de J. Fernández y la salida de Luque en las dos siguientes durante 1977, y campañas anuales entre 1978-82.

En estas campañas se excavó un área de $6 \mathrm{~m}^{2}$ hasta 1978, por niveles artificiales de $5 \mathrm{~cm}$. Inicialmente se presentará una estratigrafía dividida en dos grandes niveles (Ferrer y Marques 1978: 198-199), uno superficial y un nivel I que representaría una misma fase equivalente a Millares II, o sea Calcolítico con campaniforme en atención a la presencia de una placa de arquero, botón con perforación en $\mathrm{V}$, platos de borde engrosado y una punta de Palmela en superficie. Sin embargo, incluía igualmente cerámicas del Neolítico Final con decoraciones incisas, impresas o en relieve (Ib. 1978: lám. III), que aunque las justifican como fruto a una "fuerte perduración" de tradiciones neolíticas, sólo pueden deberse a las múltiples remociones sucedidas en la cueva antes de sus actuaciones y quizás también a la elevada pendiente de la misma (Ib. 1978: fig. 2/2), pese al cuidado puesto durante los trabajos, puesto que incluso los excavadores resaltan “el carácter algo revuelto de la zona” excavada (Ib. 1978: 198).

Esta impresión se reafirma cuando se publican los materiales recogidos de superficie (Aguado y Baldomero 1979) que muestran nuevos elementos neolíticos, y particularmente un fragmento con decoración impresa con relleno de pasta roja ( $\mathrm{Ib}$. 1979: 50-51 lám. 3/2) que señala igualmente una posible etapa del Neolítico Medio al menos en algún sector de la cueva, comentando además que en las campañas arqueológicas se habría recuperado cerámica con decoración a la almagra (Ib. 1979: 58-59), propia del Neolítico Medio y 
Final. Sin embargo, adoptan nuevamente una interpretación partidaria al verlas como fruto de perduraciones durante el Calcolítico.

Finalmente, el último trabajo presentado sobre la misma aporta novedades sobre su secuencia estratigráfica y referencias sobre un sector más extenso de $15 \mathrm{~m}^{2}$ (Ferrer y Fernández Ruiz 1988: 9, 12). Del nivel III, donde sólo se cuenta con un registro lítico "perteneciente con probabilidad a un horizonte epipaleolítico", comentan que han remitido una muestra para su datación por el laboratorio de Granada, sobre el cual se superpone fuerte un paquete estratigráfico. Tras este estrato, a 1,5 $\mathrm{m}$ de la base comienza el nivel IIC, donde coexistirían platos y fuentes de borde engrosado con cerámicas decoradas incisas, impresas, almagras y con cordones en relieve en un porcentaje del $35 \%$ que consideran del Neolítico Final ya en una fase transicional al Cobre Antiguo (Ib. 1988: 8, 10, 12).

El nivel II A/B, atribuido al Cobre Antiguo o Calcolítico Inicial, presentaría platos y fuentes de borde engrosado y borde divergente, vasos con sección en $\mathrm{S}$, algunos dientes de hoz y un $14 \%$ de cerámicas decoradas, mayoritariamente incisas, y descenso de los cordones en relieve (Ib. 1988: 10-11).

Finalmente, la última fase o nivel IB, sólo detectado puntualmente en la cueva (Ib. 1988: 11-12), atribuida al Cobre Pleno o Calcolítico Medio, cuenta con una punta de Palmela, un botón con perforación en V, platos y fuentes con borde engrosado al interior, junto a más de un $14 \%$ de cerámica decorada "con motivos cada vez menos enraizados con el sustrato".

Actualmente no disponemos de los contextos concretos de las dataciones que iremos enumerando (González Gómez et alii 1986: 1201-1202). UGRA-204 3890 210 a.C. (cal. 4720 A.C.), que es la única que muestra una desviación estadística muy elevada, UGRA-198 3550 \pm 130 a.C. (cal. 4350 A.C.), UGRA-177 3520 \pm 130 a.C. (cal. 4340 A.C.), UGRA-161 $3420 \pm 100$ a.C. (cal. 4230 A.C.) y UGRA-162 3290 \pm 110 a.C. (cal. $\mathbf{4 0 4 0 - 4 0 0 0}$ A.C.).

Valorándolas en conjunto, todas marcan un momento del Neolítico Final. Si prescindimos de la que posee una desviación estadística más elevada, el margen se estrecha al 3550-3290 a.C. (4350-4000 A.C.), y corresponderían en conjunto al Neolítico Final 2, que está representado en el registro por el nivel IIC, con la precaución que impone desconocer sus contextos y si resultan coherentes internamente, pero con la advertencia de que, aunque el carbón pueda haberse desplazado de algún estrato, está marcando el momento en que se cortó dicha madera.

Sin embargo, hemos de recalcar que creemos que la excavación furtiva de mediados de los setenta, las remociones de los cazadores, la fuerte pendiente de la cueva y quizás procesos postdeposicionales han incidido en la estratigrafía, lo que explicaría, por ejemplo, los elevados porcentajes de cerámicas decoradas en estratos que atribuyen al Calcolítico Inicial y Medio, que a nuestro entender para este último cabría mejor asignar a un Calcolítico Final avanzado, tal como se realizó en la primera memoria (Ferrer y Marques 1978: 199).

\section{Córdoba}

Cueva de los Murciélagos (Zuheros)

La cueva de los Murciélagos excavada en las campañas de 1962 y 1969, es otro yacimiento del que disponemos de una excelente serie de determinaciones (Vicent y Muñoz 1973: 112) con una fecha añadida, GRN-6926, posteriormente (Muñoz 1974: 294), ausente en alguna recopilación reciente (Chapman 1990: 50/1991: 85). A pesar de los 20 años transcurridos desde su publicación, lo que sólo le añade mayor mérito, puede considerarse aún la serie de dataciones más importante del Neolítico andaluz, lo que también invita a reflexionar. 
Del estrato V contamos con GRN-6926 4345 \pm 45 a.C. (cal. 5254 A.C.), GRN-6638 4300 \pm 35 a.C. (cal. 5223 A.C.), C.S.I.C. $-574030 \pm 130$ a.C. (cal. $4900-4850$ A.C.) de cereal, y C.S.I.C. $564010 \pm 130$ a.C. (cal. 4760-4730 A.C.).

En el estrato IV, de un mismo conjunto de semillas de trigo y bellotas de un silo, se obtuvieron tres dataciones diferentes, C.S.I.C. $-534240 \pm 130$ a.C. (cal. $5200-5080$ A.C.), C.S.I.C. $-544240 \pm 130$ a.C. (cal. $\mathbf{5 2 0 0 - 5 0 8 0}$ A.C.) y GRN-6169 $\mathbf{4 2 0 0} \pm 45$ a.C. (cal. 5064 A.C.). Otras determinaciones son, C.S.I.C. 55 $4220 \pm 130$ a.C. (cal. $5190-5070$ A.C.) de semillas, C.S.I.C. $584150 \pm 130$ a.C. (cal. 4990 A.C.) y GRN-6639 $4075 \pm 45$ a.C. (cal. 4923 A.C.) sobre semillas.

El estrato III sólo proporcionó una datación, C.S.I.C.-593980 \pm 130 a.C. (cal. 4800 A.C.), pero presenta también cerámica incisa de los campos de urnas (sic), ibérica, romana y un clavo de hierro (Quadra y Vicent 1964: 71; Vicent y Muñoz 1973: 14).

Una de las investigadoras, Muñoz Amilibia (1974: 293-294) consideró en su momento al yacimiento contemporáneo al neolítico antiguo con cerámica cardial, a partir de la antigüedad de las dataciones y la presencia de otra variedad de cerámica impresa "en zig-zag o dientes de sierra (...) con amplios paralelos en el neolítico antiguo mediterráneo".

No obstante, si procedemos a una cuidadosa revisión del conjunto artefactual de estos tres estratos se revela claramente que los estratos $\mathrm{V}$ y IV son el mismo, inclusive con piezas procedentes del mismo recipiente en ambos estratos, y los materiales neolíticos del E. III probablemente procedan de remociones superiores que los elevan desde el E. IV. Esta apreciación se ve reforzada por la serie de dataciones que en su totalidad oscilan entre 4345 y el 3980 a.C. (5254-4800 A.C.), que creemos perfectamente representativas del Neolítico Medio.

\section{Sevilla}

Cueva Chica de Santiago (Santiago de Cazalla)

Cueva Chica de Santiago, situada en las estribaciones de Sierra Morena, fue excavada en 1976 y 1980 por P. Acosta, obteniendo una estratigrafía de más de tres metros, pero cuya monografía definitiva aún no ha sido publicada. La falta de otras cuevas excavadas con secuencias neolíticas en Sevilla dificulta igualmente la evaluación de la amplia serie de dataciones obtenidas.

Del nivel asignado al Neolítico Inicial (Pellicer y Acosta 1982: 58; Kunst 1992: 389-397), contamos con GaK-8952 5940 \pm 180 a.C. (cal. 6650 A.C.) y GaK-8947 5290 \pm 230 a.C. (cal. 6040 A.C.), que muestra un registro típico del Neolítico Medio, tal como sucede en la Cueva de los Murciélagos, con predominio de la cerámica a la almagra (Pellicer y Acosta 1982: fig. 6/6, 8, 10-11, 16), junto con algunas impresiones de conchas "cardialoides".

A partir de información personal en 1989 del director del laboratorio japonés, M. Kunst (1992: 389) publica un nueva determinación, de la que desconocemos el contexto pero que quizás venga de estos niveles dada su antigüedad, GaK-8951 5090 180 a.C. (cal. 5930-5870 A.C.).

Por el contrario, una muestra de la campaña de 1980, presumiblemente de estos niveles pues Acosta señala que esperaba una fecha de ca. 5050 a.C., al ser datada por el laboratorio de Granada (González Gómez et alii 1987: 385), UGRA-254 4210 \pm 120 a.C. (cal. 5070 A.C.) resulta perfectamente acorde con las series de la Cueva de los Murciélagos (Zuheros): 4345-4075 a.C. (5254-4923 A.C.) y la Cueva del Toro (Antequera) 4450-4370 a.C. (5320-5260 A.C.) procedentes de contextos del Neolítico Medio.

Pertenecientes al Neolítico Final (Pellicery Acosta 1982: 58; Kunst 1992: 389-397) se citan las determinaciones, GaK-8949 4430 \pm 150 a.C. (cal. 5290 A.C.) y GaK-8948 3570 \pm 120 a.C. (cal. 4350 A.C.), que muestran una llamativa discrepancia, pues si la primera nos remite a cronologías de comienzos del Neolítico 
Medio, lógicamente difícilmente aceptables, la segunda marca el tránsito del Neolítico Final 1 al Neolítico Final 2 y sería muy interesante conocer su contexto y registro asociado ya que es la única muestra de la serie del laboratorio japonés que resulta acorde con lo esperado.

Finalmente, del segundo nivel calcolítico (Acosta y Cruz-Auñón 1981:345) procede GaK-89503150 \pm 120 (cal. 3950-3830 A.C.) que nos remite a contextos del Neolítico Final antes que del Calcolítico Inicial.

En conclusión, Cueva Chica de Santiago presenta una serie difícilmente asumible, tal como también consideran genéricamente Fortea y Martí (1984-85: 185-186), lastrada por su procedencia mayoritaria del laboratorio japonés de Gakushuin, que por esas fechas resultaban siempre sistemáticamente más antiguas. El contraste con la muestra obtenida en el laboratorio de Granada resulta muy interesante porque parece que confirma esta impresión al ofrecer una determinación acorde con el contexto del Neolítico Medio que creemos se estaba datado. Es posible que cuando conozcamos el contexto quizás 3570 a.C. (4350 A.C.) sea también aceptable para niveles del Neolítico Final.

\section{Cádiz}

Cueva de la Dehesilla (Jerez de la Frontera)

La Cueva de la Dehesilla, inserta en las Cordilleras Béticas y definida por P. Acosta (1986: 143) como "la estratigrafía que menores dificultades ha presentado en Andalucía Occidental para establecer su periodización" es, sin embargo, otra de las más polémicas (Fortea y Martí 1984-85: 185-186) junto con la Cueva de Nerja. Excavada en dos campañas realizadas en 1977 y 1981, la reciente publicación de la monografía (Acosta y Pellicer 1990: 87-89; Kunst 1992: 387-404) permite una más correcta valoración del yacimiento, si bien no incidiremos sobre los niveles del Neolítico Final al carecer de dataciones.

De casi la base de la estratigrafía y procedente de la campaña de 1981, donde hubo un mayor número de subdivisiones en estos estratos, el N.13, UGRA-259 4310 \pm 100 a.C. (cal. 5230 A.C.) (González-Gómez et alii 1987: 385) es considerada del Neolítico Antiguo.

En el nivel 11 (N.10 de 1981), GaK-8953 5720 \pm 400 a.C. (cal. 6460 A.C.) (Pellicer y Acosta 1982: 56), sería correspondiente al final del Neolítico Antiguo.

En el nivel 10 (N.9 o 8 de 1981) o Neolítico Medio, GaK-8954 5170 \pm 200 a.C. (cal. 5960 A.C.) y GaK-8955 5090 \pm 170 a.C. (cal. 5930-5870 A.C.) (Ib. 1982: 56).

Es obvio que no puede aceptarse para el mismo nivel GaK-8958 1170 \pm 180 a.C. (cal. 1400 A.C.), sobre huesos humanos. Sin embargo, Zilhão (1993: 40) ha enfatizado que no hay razones a priori para excluir de que se trate de un enterramiento de la "prehistoria final" lo cual "debería sugerir que el grado de intrusiones post-deposicionales es mucho más elevado que el que reconocen los autores". El problema de esta suposición, que no se ve apoyada por ningún tipo de ajuar en el enterramiento o con referencias sobre dibujos de perfiles, es asumir que esta determinación sobre huesos del laboratorio japonés es correcta mientras las otras no lo son, y remitirnos a un momento del Bronce Final que debería haber atravesado y alterado los estratos precedentes del Neolítico Final y Calcolítico.

Del nivel 8 (N.6 de 1981) del final del Neolítico Medio, GaK-8956 3970 160 a.C. (cal. 4790 A.C.). Del mismo nivel procede GaK-8957 6250 160 a.C. (cal. 7250-7100 A.C.) (Acosta y Pellicer 1990: 88-89), también para este final del Neolítico Medio, que resulta obviamente difícilmente admisible.

En la monografía, la tabla de la secuencia del yacimiento muestra una incorrecta presentación y dificulta en gran medida la comprensión al investigador si desea obtener una visión rápida y general de la cueva (Acosta y Pellicer 1990: 142, fig.7). 
Como fecha propia del inicios de Neolítico Antiguo se pone 6250 a.C., que como hemos visto pertenece al nivel superior del Neolítico Medio.

En su emplazamiento correcto del Neolítico Antiguo aparece el 4310 a.C., sin embargo es la única que aparece como calibrada, lease 5455-4960 A.C., sin indicarse este hecho, lo que se repite de otra forma en el texto cuando sólo se pone B.P. (Ib. 1990: 87), mientras todas las restantes dataciones aparecen a.C., y para mayor confusión y bajo el mismo epígrafe de laboratorio, es precedida por una fecha cuyo origen desconocemos denominada 7450 \pm 500 B.P., que curiosamente se aproxima a la edad esperada por Acosta (González-Gómez et alii 1987: 385) de un 7500 B.P.

La fecha del 5720 a.C. (6460 A.C.) aparece en el Neolítico Antiguo, pero en vez de estar situada en el final de este periodo donde le corresponde según el nivel, se ubica hacia mediados de dicho periodo.

En sus emplazamientos correctos aparecen otras tres fechas, 5170 a.C. (5960 A.C.), 5090 a.C. (5930-5870 A.C.) de inicios del Neolítico Medio, y 3970 a.C. (4790 A.C.) del final de dicho periodo.

Recapitular sobre esta serie de dataciones no deja de resultar especialmente problemático, ya que además recientemente (Zilhão 1993: 41-42) se ha afirmado que esta estratigrafía "no puede ser objeto de una consideración científica seria", criticándose entre otros aspectos la velocidad en que fueron realizadas las campañas de 1977 y 1981, sin atenderse suficientemente a los diferentes buzamientos que presenta el estrato del Neolítico Inicial en la base de la cueva.

A nuestro juicio, y revisado el conjunto artefactual de la cueva, no tenemos claro la existencia de ese presunto Neolítico Inicial o Antiguo, y creemos que nos encontraríamos ante niveles propios del Neolítico Medio. Aceptada esta premisa, lo lógico sería dar por buenas dos dataciones entre los niveles 14 y 6 , el 4310 a.C. para el nivel 13 próximo a la base y el 3970 a.C. del nivel 8 (N.6 de 1981) para su etapa final. Ambas se corresponderían bien con las series de la Cueva de los Murciélagos y Cueva del Toro, pero ello implica coger una determinación del laboratorio de Granada, UGRA-259 4310 100 a.C. (cal. 5230 A.C.), y al menos otra del laboratorio de Gakushuin, GaK-8956 3970 170 a.C. (cal. 4790 A.C.), del final del Neolítico Medio que no obstante cuenta con una elevada desviación estadística y debe utilizarse con más prudencia.

Desde un punto de vista partidario de interpretar el registro artefactual como Neolítico Inicial o Antiguo, lo lógico y coherente habría sido desechar ambas fechas, especialmente la primera, lo que no se hace.

Hay que admitir que las fecha del 5720 a.C. (6460 A.C.) para el final del Neolítico Inicial, 5170 a.C. (5960 A.C.) y 5090 a.C. (5930-5870 A.C.) para inicios del Neolítico Medio y 3970 a.C. (4790 A.C.) para el final del Neolítico Medio podrían tener cierto sustento. Sin embargo, obviando momentáneamente el contraste de los artefactos recuperados, la primera fecha del $5720 \pm 400$ a.C. posee una desviación estadística muy acentuada que permite dudar de su fiabilidad.

Más problemático resultaría rechazar las dos muestras de inicios del Neolítico Medio, $5170 \pm 200$ a.C. y $5090 \pm 170$ a.C., a pesar de su notable desviación estándar. Sin embargo, ello plantearía la necesidad de enmarcar el Neolítico Medio entre el 5200-4000 a.C. (6020-4830 A.C.), lo que no parece ratificarlo ni las dataciones de la Cueva de los Murciélagos ni las de la Cueva del Toro, e implicaría un Neolítico Medio andaluz paralelo al Neolítico Inicial cardial del País Valenciano.

Lo adecuado habría sido contrastar los resultados en otro laboratorio. Sin embargo parece que, o no se realizó o no se pudo intentar por imperativos financieros. Ya observamos cómo la única datación de UGRA de ese supuesto Neolítico Antiguo ponía en entredicho la fecha ofrecida por GaK al distanciarse ambas 1.410 años. Ello incluso se aprecia en la interpretación de estos investigadores los cuales, a pesar de las dataciones obtenidas, proponen otras teóricas del 4500-4000 a.C. para el Neolítico Medio A y 4000-3500 a.C. para el Neolítico Medio B, si bien el Neolítico Antiguo lo retrotraen al 6000-4500 a.C.

En definitiva, frente a actitudes extremistas, la solución más razonable serían nuevas dataciones que sirvieran de contraste, y si no se dispusiera de muestras, proceder a nuevas excavaciones para clarificar 
una secuencia que cuando esté más ratificada por nuevas determinaciones radiocarbónicas debe ser paradigmática en Andalucía Occidental dadas sus excepcionales condiciones.

\section{CALCOLÍtico}

\section{Málaga}

Cortijo del Tardón. sep. 1 (Antequera)

El sepulcro del Tardón se sitúa en el Cortijo de Villanueva del Rosario, en un estrecho valle por el cual se comunica tanto hacia la Depresión de Antequera aprovechando el arroyo de la Yedra, como accediendo a la depresión de Colmenar, siguiendo el río Parroso, tras cruzar el puerto de la Fresneda.

En él se han realizado dos campañas de excavación, una en 1984 dirigida por J.E. Ferrer Palma, y otra durante 1985 junto a J. Fernández Ruize I. Márquez (Ferrer et alii 1987), pudiéndose localizar dos estructuras de enterramiento, la sep. A expoliada, y con parte del ajuar en la colección particular de F. Álvarez Curiel, y la sep. B, que aportó los mejores datos estructurales y funerarios. En general, se tratan de dos sepulturas colectivas rectangulares que aprovechan las calizas naturales en cabecera y pie, mientras a los lados dispusieron lajas transversales, de $4 \mathrm{~m}$ de largo $\mathrm{x} 1 \mathrm{~m}$ de ancho, con $1 \mathrm{~m}$ de profundidad en la A y $0,5 \mathrm{~m}$ en la B.

Dado que el artículo se trata de un informe preliminar desconocemos el numero de enterramientos en cada sepultura, así como la correspondiente distribución del ajuar a cada tumba. No obstante, a nivel general destaca la presencia de un cuenco y una olla con decoración campaniforme incisa, un brazalete de arquero, una punta de Palmela, un puñal de lengüeta, dos espirales de cobre y varios punzones de metal.

De la sepultura 1, ¿la sep. A?, se obtuvo UGRA-260 1580 \pm 70 a.C. (cal. 1880-1790 A.C.) (González-Gómez et alii 1987: 386), que resulta demasiado reciente ya que marca un momento de tránsito entre el Bronce Medio 1 y 2, mientras que como mucho podría ser atribuida en función a su ajuar a la primera etapa del Bronce Inicial. No cabe descartar, sin embargo, posibles reutilizaciones de la sepultura, quizás no acompañadas por ajuar. En todo caso, deberá esperarse a un informe antropológico sobre las sepulturas para conocer la procedencia de la muestra y el número de enterramientos en los mismos.

\section{Córdoba}

\section{Cerro del Castillo (Monturque)}

La realización de un sondeo en el Cerro del Castillo durante 1987 (López Palomo 1990), se ha visto acompañada por una rápida publicación de la memoria (Ib. 1993) que permite evaluar con cierto detalle las determinaciones obtenidas (González Gómez 1992: 134-135) en una estratigrafía de casi $7 \mathrm{~m}$. de potencia, excavada por niveles artificiales.

De la fase I, o Calcolítica, que corresponde a los niveles 44-33 o estratos XI-X, se tomó inicialmente una muestra del nivel 44 sobre la roca, que fue considerada insuficiente por el laboratorio de la Universidad de Granada, por lo que se envió el carbón recogido en distintos puntos del nivel 42, UGRA-323 1440 \pm 110 a.C. (cal. 1680 A.C.) que resulta incompatible con la presencia de cerámica campaniforme impresa (López Palomo 1993: 294) en el Estrato XI que cabe asignar a comienzos del Calcolítico Final.

El excavador justifica el problema en la inversión estratigráfica que afecta al sector occidental del sondeo por su proximidad a la cara interna de la muralla del Castillo, que trató de dejar aislada y que a su juicio 
no muestra intromisiones a nivel del registro cerámico, de ahí que rechaza la determinación. El tratarse de una muestra obtenida de carbones de distintos puntos del nivel facilitaría la mezcla de carbón procedente de los niveles superiores. El intervalo máximo inferior al calibrar la determinación señala un 1944 A.C., que indicaría como mucho un momento final del Bronce Inicial, lo que puede señalar que la contaminación quizás provenga de filtraciones por movimientos post-deposiciones de partículas de carbón desde el estrato IX, y no necesariamente del estrato VIII como sugiere López Palomo (1993: 290).

En el estrato X, donde coexisten campaniforme impreso y ahora también inciso (Ib. 1993: 294), se tomó una determinación del nivel 36, UGRA-303 2170 \pm 160 a.C. (cal. 2850-2620 A.C.). El problema principal surge al confrontar una determinación propia de inicios del Calcolítico Medio en un teórico momento avanzado del Calcolítico Final. No obstante, si tomamos la banda superior de la calibración, ésta llega al 2200 A.C., que podría aceptarse para este momento.

Por otra parte, López Palomo (1993: 290) comenta su intención de realizar nuevos análisis de $C^{14}$ de los niveles 42 y 36 , con lo que en el futuro probablemente se podrá clarificar la secuencia temporal calcolítica del poblado.

Pertenecientes a la fase II, que incluye los niveles 32-28 o estrato IX, que asignó inicialmente a la transición Calcolítico-Bronce (Ib. 1990) y posteriormente agregó el Bronce Inicial (Ib. 1993:312), pese a la presencia de niveles de incendio, carecemos de determinaciones que habrían ayudado a precisar mejor la fase calcolítica precedente, ahora que el campaniforme ha desaparecido salvo dos fragmentos aislados.

\section{Sevilla}

\section{Amargillo II (Los Molares)}

El poblado de Amargillo II está asociado a unos 1,5-2 km con una necrópolis megalítica de unos 6 enterramientos donde destacan los dólmenes de Cañada Real (Carriazo 1974: 152-154) y del Palomar excavados en 1967 y 1981. En él se han realizado dos campañas de excavación, una primera de sondeo en 1986 y otra sistemática en 1987, dirigidas por R. Cabrero (1987 y 1990). Este poblado de grandes dimensiones, $20 \mathrm{Ha}$, aunque recientemente aparentemente reducidas a $4 \mathrm{Ha}$ (Cabrero en Hedges et alii 1995: 206) controlaba la ruta después denominada Cañada Real, que iba de Utrera a Morón de la Frontera.

El poblado presenta tres niveles (Cabrero 1990: 276-277). Uno superficial de 0,55 m removido donde se localizan algunos campaniformes marítimos y puntas de Palmela del Calcolítico Final. Un segundo nivel, desde $0,55 \mathrm{~m}$. hasta $0,90 \mathrm{~m}$, que presentaba un enteramiento individual de una joven en posición fetal, y en otro sector, un depósito de mineral de cobre. Y finalmente, el tercer nivel que alcanza en algún punto los 2,50 m de profundidad, presentaba siete cabañas circulares excavadas en el suelo de unos $2 \mathrm{~m}$ de diámetro y hogares también excavados al exterior, de $1 \mathrm{~m}$ de diámetro, asignables al Calcolítico Medio con platos de borde engrosado.

La autora comenta el envío de dos determinaciones por $C^{14}$ (Cabrero 1990: 277) de las que aún desconocemos sus resultados. No obstante, una muestra remitida en 1992 de la campaña de 1986, OxA-3971 2080 \pm 65 a.C. (cal. 2560-2500 A.C.) (Hedges et alii 1995: 206) nos señala un momento avanzado del Calcolítico Medio.

\section{Cerro de la Cabeza (Valencina de la Concepción)}

Bajo la actual población de Valencina de la Concepción se encuentra uno de los poblados más importantes de Andalucía, con más de 100 Ha de extensión, alrededor de cual se distribuyen grandes sepulcros colectivos 
en tholos como el Cerro de la Cabeza (Fernández Gómez y Ruiz Mata 1978), La Pastora (Almagro Basch 1962), Ontiveros o Matarrubilla (Obermaier 1919).

Este poblado se ha visto afectado tanto por el crecimiento de la población de Valencina de la Concepción, como ciudad dormitorio de Sevilla, como por la ausencia de un programa de excavaciones sistemáticas en el poblado, aunque sí contamos con una progresiva amplia serie de excavaciones de urgencia en solares antes de su urbanización, iniciadas en 1971, que suelen quedar reducidas normalmente a un simple informe de la excavación, con la feliz excepción del corte C (Fernández y Oliva 1985) del cual proviene también el único análisis faunístico del poblado.

En 1976 se realizó el desmonte de una de las áreas del poblado, el Cerro de la Cabeza, lo que permitió la primera y única gran excavación en extensión (Fernández y Oliva 1980), donde pese a la destrucción de numerosas estructuras se pusieron al descubierto dos grandes zanjas de alrededor de $4 \mathrm{~m}$ de anchura con secciones en $\mathrm{U}$ o $\mathrm{V}$, múltiples silos generalmente de sección semicircular, base plana y profundidad entre 1 y $2 \mathrm{~m}$, cinco pozos de $1 \mathrm{~m}$ de diámetro que alcanzan a veces $l o s 10 \mathrm{~m}$ de profundidad y una cabaña que probablemente contaba con un techo a dos aguas de acuerdo con la distribución de los postes dentro de la misma.

Del pozo $\mathrm{n}^{\mathrm{Q}} 1$, que proporcionó sucesivamente a 6,21 m un ídolo falange, a 7,04 $\mathrm{m}$ un ídolo cilíndrico, a 7,91 m un ídolo antropomorfo y a 9,56 m otro ídolo antropomorfo, se tomó a esta última profundidad la muestra GIF-4.028 1960 \pm 110 a.C. (cal. 2450-2410 A.C.) (Fernández Gómez y Oliva 1980: 43 y 1985:117). Del nivel superior conservado del pozo 31 , se obtuvo I-10.187 2100 \pm 105 a.C. (cal. 2570-2510 A.C.) (Fernández Gómez y Oliva 1980: 43 y 1985:117), y a posteriori, se localizaron a 6,30 m un ídolo falange, a 7,75 m un ídolo sobre hueso largo y finalmente a $8,10 \mathrm{~m}$ otro ídolo falange.

Es importante recalcar que el ídolo antropomorfo se encuadre en el Calcolítico Final, tal como sucede con otro procedente de El Malagón (Cúllar, Granada).

Otras muestras que se remitieron de huesos del nivel inferior del Corte $\mathrm{C}$ resultaron insuficientes (Fernández Gómez y Oliva 1985: 117). No obstante, de este poblado procede una muestra de huesos recogida por

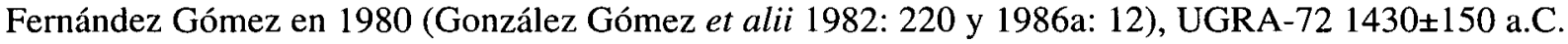
(cal. 1680 A.C.), aparentemente destinada a datar un momento del Calcolítico Final pero que resultó demasiado moderna pues su autor no ha hecho referencia sobre la misma, que remite a un momento de finales del Bronce Medio.

\section{El Negrón (Gilena)}

El poblado de El Negrón, vinculado con la necrópolis de cuevas artificiales de Antoniana, ha sido excavado durante tres campañas, un sondeo inicial en 1986 y una primera campaña sistemática en 1987 dirigidas por R. Cruz-Auñón y E. Rivero (1987 y 1990) y otra en 1990 dirigida en solitario por Cruz-Auñón.

La campaña de 1986 tuvo como elemento más significativo la excavación de la estructura $V$ que presenta un largo máximo de 2,40 m y una profundidad de 1,39 m (Cruz-Auñón y Rivero 1987: 177 fig. 2-3; 178) correspondiente a una cabaña semienterrada excavada en margas arcillosas con un hogar de piedras y adobes en su nivel I, que presenta cerámica tradicionalmente asignable al Calcolítico Inicial, incluyendo cerámica pintada con motivos en reticulado, y un nivel II que corresponde al relleno de la estructura por derrumbamiento de sus paredes o cubierta.

En la campaña de 1987, se excavó otra cabaña similar (Cruz-Auñón y Rivero 1990: 278-279, fig. 1-2), la estructura I, con unas dimensiones de 4 × $3 \mathrm{~m}$ y profundidad máxima de $1,89 \mathrm{~m}$, que presenta al igual que la primera una rampa de acceso, hogar de piedras en el nivel de base, cuatro huellas de postes y en los niveles 
superiores ladrillos de adobe que delimitan un agujero central de $2 \mathrm{~m}$ de diámetro correspondiente a una claraboya de salida de humos, destacando en su registro la presencia de "tazas carenadas" y un peine de hueso.

De uno o de los dos hogares se disponen de una seriación de dataciones, GrN-? 2380 $₫ \pm 35$ ? a.C. (cal. 2915 A.C.), GrN-? 2300 \pm 35 a.C. (cal. 2884 A.C.) (Cruz-Auñón et alii 1992: 280) y 2350 \pm 35 a.C. (cal. 2906 A.C.) (Cruz-Auñón et alii 1993: 379), que son particularmente importantes porque marcan la continuidad de las tradicionales "tazas carenadas" durante inicios del Calcolítico Medio.

Finalmente, la campaña de 1990 (Ib. 1993: 375) ha aportado una nueva cabaña, la estructura VII.

\section{Universidad Laboral de Sevilla (Alcalá de Guadaira)}

Este poblado, situado en las inmediaciones de la Universidad Laboral de Sevilla, se encuentra en la cima de un cerro inmediato a una gravera que explotaba las gravas de arrastre de un afluente, probablemente entonces navegable, del río Guadalquivir.

En el mismo, F. Fernández Gómez y J.A. de la Sierra (1985) excavaron tres fondos de cabaña, del que destaca el fondo de cabaña no 3 , con 1,50 m de diámetro y 1,20 m de profundidad, donde se documentó un cuenco campaniforme con decoración incisa y ónfalo, varios fragmentos informes con decoraciones impresas o incisas y un crisol cerámico.

La determinación se obtuvo de una acumulación de carbones, ceniza y varias piedras quemadas a $c a$. $1 \mathrm{~m}$ de profundidad de fondo de cabaña, I-10.764 1240 120 a.C. (cal. 1440 A.C.) (Fernández Gómez y Sierra 1985: 13,19), de la cual dedujeron una pervivencia de los campaniformes en el Valle del Guadalquivir "hasta los años finales del II milenio", idea también aceptada por Martín de la Cruz (1989: 125).

Esta observación resulta difícilmente aceptable, aunque fue coherente con el dato obtenido por el laboratorio, e incluso si observamos el intervalo máximo de la determinación calibrada 1737-1129 A.C., la fecha más antigua nos remite a la fase final del Bronce Medio, lo que implica la necesidad de rechazar esta determinación, pudiendo incluso deberse a un error del propio laboratorio durante su procesado.

\section{Cádiz}

\section{Las Viñas. Cantarrana (Puerto de Santa María)}

Este poblado de 0,6 Ha, situado en una zona de dunas eólicas, presenta varios fondos de cabaña y un importante número de silos como es característico en todos los poblados del Neolítico Final-Calcolítico Inicial.

Procedentes del área de los silos contamos con dos muestras de conchas, UGRA-370 3000 \pm 60 a.C. (cal. 3710 A.C.) del silo $n^{\circ} 16$ y UGRA-369 2850 \pm 90 a.C. (cal. 3630-3550) (Giles et alii 1993-94: 43-44), que en principio marcan un momento avanzado del Neolítico Final, en tránsito con el Calcolítico Inicial, pero dado que se trata de conchas, presumiblemente nos está remitiendo a un momento más antiguo del que debería estar datando, por lo que quizás ambas podrían incluirse en los comienzos del Calcolítico Inicial.

\section{Huelva}

Papauvas (Aljaraque)

El poblado de Papauvas se localiza en el antiguo estuario de los ríos Tinto y Odiel, en su margen occidental. Las excavaciones se inician en 1976 y 1977 codirigidas por D. Ruiz Mata y J.C. Martín de la Cruz, y a partir de 1979-83 y 1986-87 exclusivamente por Martín de la Cruz (1985, 1986a, 1987c y 1993: 442). 
El poblado presenta una mayoritaria ocupación durante el Neolítico Final (Fase I A-B) y Calcolítico Inicial (Fase II-III), con prolongación puntual durante el Calcolítico Medio (Fase IV), con platos de borde divergente engrosados al exterior o a ambos lados, al que se asigna exclusivamente el fondo $\mathrm{n}^{\mathrm{o}} 10$ (Martín de la Cruz 1986a: 192-197), habiéndose documentado más de 13 "fondos de cabaña" y numerosas zanjas de las fases iniciales.

A pesar de la entidad de las excavaciones, cerca de 200 cortes, aunque muchos superficiales, no disponemos de una serie muy amplia de dataciones. Correspondiente al estrato II de la fase II procede CSIC- $4852890 \pm 120$ a.C. (cal. 3640 A.C.) (Ib. 1985: 187).

Por otra parte también del estrato II; fondo n⿳ 10 , Sector C, Corte D.3.1, en el cual el estrato III corresponde al superficial y el estrato I sólo tiene $10 \mathrm{~cm}$ y apenas artefactos, ha sido datado a partir de conchas de Tapes decussatus CSIC-654 2160 \pm 50 a.C. (cal. 3033 A.C.) (Ib. 1986a: 192, 314). Esta determinación rompe la interpretación de Martín de la Cruz ya que atribuye el nivel a ca. 2500 a.C.. Sin embargo al tratarse de una muestra sobre concha lo lógico sería que resultase más antigua de lo habitual, por lo que en teoría debería ser aún más reciente. Habrá que esperar, no obstante, a que se realice un estudio sobre el efecto de reserva para el $\mathrm{C}^{14}$ en los estuarios atlánticos del Tinto y Odiel para hacer una valoración precisa.

Por otra parte, también se comenta el envío al C.S.I.C. de tres muestras de carbón, conchas y huesos del corte G-14.1 (Martín de la Cruz et alii 1990: 251), correspondientes al Sector B del poblado, que presenta una gran zanja de cerca de $7 \mathrm{~m}$ de largo y $3 \mathrm{~m}$ de potencia estratigráfica homogénea (Martín de la Cruz 1987b: 315).

Desconocemos el contexto de otra muestra de huesos (González Gómez 1992: 136) obtenida a 2,2 m de profundidad, procedente de la campaña de 1981 , UGRA-329 3560 \pm 80 a.C. (cal. 4350 A.C.), que es hasta el momento la más antigua del poblado, y de ser aceptable indicaría por primera vez un momento del Neolítico Final confirmando el registro artefactual.

\section{BRONCE INICIAL Y MEDIO}

\section{Málaga}

Ronda la Vieja-Acinipo (Ronda)

El yacimiento de Acinipo comienza a ser investigado exclusivamente en sus niveles romanos por Rafael Puertas Tricas con dos campañas en el teatro (1967) y en la ciudad (1980). Entre 1982-83 P. Aguayo inicia dos campañas en los niveles pre- y protohistóricos del poblado. Finalmente, a partir de 1985 se reanudan las excavaciones dentro de un Proyecto de Investigación aprobado por la Junta de Andalucía, dirigido por P. Aguayo y M. Carrilero (Aguayo et alii 1987), continuando con campañas en 1986 y 1988.

Las excavaciones se han centrado particularmente en una pequeña meseta individualizada de la zona oriental del yacimiento. Allí se han detectado dos terrazas escalonadas, localizándose en la superior una cabaña oval, mientras en la inferior se han documentado dos arcos de muro de otras dos cabañas. Los niveles de ocupación y derrumbe de la cabaña superior han sido datados por I-? $1700 \pm 80$ a.C. (cal. 2020-1980 A.C.) y I-? 1630 \pm 100 a.C. (cal. 1910 A.C.), correspondientes a los niveles de uso de la cabaña e I-? $1030 \pm 90$ a.C. (cal. 1250-1200 A.C.) procedente del derrumbe. Todas estas muestras han sido enviadas para obtener una segunda determinación de las mismas cuando ha sido posible (Aguayo et alii 1991: 311, 314).

El material asociado a estos niveles muestra dos campaniformes inicisos, un botón cónico de hueso con perforación en V, y en los niveles del interior de la cabaña, un brazalete de arquero (Aguayo et alii 1987: 298), que resultan coherentes con la datación del 1700 a.C. (2020-1980 A.C.) propias de un Bronce Inicial, 
pero que chocan con un momento de tránsito del Bronce Inicial al Bronce Medio que marca el 1630 a.C. (1910 A.C.). La determinación reciente procedente del derrumbe, por otra parte, podría haber sido originada por intrusiones procedentes de niveles superiores.

\section{Cádiz}

Monte Berrueco (Medina Sidonia)

El Monte Berrueco contaba con dos elevaciones, de las cuales el punto más bajo fue elegido como área de hábitat pero su explotación como cantera ha destruido gran parte del mismo. En 1982 se realizó una campaña de sondeo dirigida por J.L. Escacena que documentó una larga estratigrafía entre el Bronce Inicial y el Bronce Final, y se obtuvieron dos determinaciones (Escacena y Frutos 1985: 19-20; Escacena y Berriatua 1985: 228) que han sido consideradas propias del Bronce del Sudoeste (Lull et alii 1992: 268) a pesar de su emplazamiento en Cádiz.

El estrato I, en sus cortes A y B, presentó tres enterramientos individuales en fosa al exterior de una "vivienda" con un paramento recto, sin ajuar, y que iban acompañados de pequeños cristales de cuarzo posiblemente como señalizadores del enterramiento. Aunque el estrato I es considerado de transición entre el Calcolítico y Bronce, concretamente "muy de finales del Calcolítico" (Escacena y Frutos 1985: 23; Pellicer 1989: 160), sin embargo, el elemento más evidente, un fragmento de campaniforme está descontextualizado al proceder de un relleno del estrato IV (Escacena y Frutos 1985: 24 nota 32, 39) al producirse un aterrazamiento, no obstante, hay ausencia de cerámicas carenadas y se recuperó un fragmento de una punta de flecha.

Sin embargo, creemos que esta ocupación debe atribuirse a comienzos del Bronce Inicial de acuerdo con el nuevo ritual de enterramiento en el interior de los poblados, donde podría producirse perfectamente la pervivencia de alguna cerámica campaniforme, sin descartar que en otros puntos del poblado pueda existir una ocupación calcolítica que posiblemente haya comenzado en el Calcolítico Final tal como apuntan Escacena y Frutos. Por otra parte, siempre incide el problema metodológico de considerar estos momentos como una prolongación del Calcolítico Final o ya propiamente del Bronce Inicial, alternativa esta última por la que nos inclinamos.

De la base del estrato II, corte B, se obtuvo I-? 1670 \pm 80 a.C. (cal. 1960 A.C.) que marcaría un momento final del Bronce Inicial 2 que resultan coherentes con la presencia de cerámicas carenadas a media altura. En la parte superior del mismo corte y estrato se documentaron dos nuevos enterramientos individuales, que mantienen el uso de los pequeños cristales de cuarzo, y uno de los cuales quizás presentaba como ajuar un cuchillo-puñal con cuatro remaches ya que apareció en el área inmediata afectada por la cantera (Escacena y Frutos 1985: 29).

La ausencia de cambios constructivos entre los estratos I y II creemos que apoya la continuidad entre ambos y su perduración hasta un momento final del Bronce Inicial, ya que aunque la muestra fue obtenida a comienzos del estrato no se advierten innovaciones artefactuales o estructurales en la parte superior del estrato II.

Es importante reseñar que las posibilidades que ofrece Monte Berrueco se encuentran actualmente inexploradas salvo este breve sondeo. Se trata, a pesar de encontrarse afectado por una cantera, de una de las estratigrafías con más posibilidades de aportar datos indicativos del transito del Calcolítico al Bronce, y el posterior desarrollo del Bronce Inicial en Andalucía Occidental. En este sentido, una datación de los huesos de alguno de los enterramientos del estrato I permitiría clarificar si realmente nos encontramos ante la transición del Calcolítico al Bronce, o ya en un momento del Bronce Inicial. 


\section{BRONCE FINAL}

\section{Málaga}

Acinipo (Ronda)

Tras un hiatus poblacional en el sector oriental del poblado de Acinipo (vide supra), se reanuda la ocupación con la construcción de una terraza sobre la cual se disponen 3 cabañas de planta rectangular (n⿳0 3-5) y 2 circulares ( $\mathrm{n}^{\mathrm{o}}$ 1-2), con similar orientación al sur y en disposición alineadas (Aguayo et alii 1986: 37 fig. 4, 46 y 1987: 295 fig. 1, 300), todas ellas contemporáneas salvo la cabaña no 5 (Ib. 1986: 46). Este nivel presenta cerámica a torno, siendo datado por I-? $820 \pm 90$ a.C. (cal. 910 A.C.), I-? 700 \pm 90 a.C. (cal. 810 A.C.) e I-? 690 \pm 180 a.C. (cal. 810 A.C.) (Aguayo et alii 1991: 311), no obstante, la frecuente limpieza de las mismas y el hecho de que el interior de estas cabañas se encontraba muy alterado por reconstrucciones posteriores, salvo algunos sectores de la cabaña circular 1 entre el hogar central y la puerta (Aguayo et alii 1986: 40), dificulta realizar precisiones sobre el registro artefactual con la información disponible.

\section{Morro de Mezquitilla (Vélez-Málaga)}

El poblado fenicio de Morro de Mezquitilla se sitúa en la desembocadura oriental del río Algarrobo, a $800 \mathrm{~m}$ al oeste del poblado fenicio de Chorreras y antes del de Toscanos, que se emplaza en el río Vélez. Tras el descubrimiento de la necrópolis fenicia de Trayamar durante 1930 en la desembocadura occidental del río Algarrobo, en 1967 se desarrolló una primera campaña simultánea en Trayamar y Morro de Mezquitilla dirigidas por H.G. Niemeyer y H. Schubart (1975; Schubart y Niemeyer 1976). Las actuaciones se reanudaron con tres nuevas campañas dirigidas por Schubart en 1976, 1981 y 1982 (Schubart 1977; 1979; 1983 y 1985), donde además de las fases fenicias se documentó una importante ocupación calcolítica o fase A y algunos materiales del Bronce Final.

De acuerdo con la estratigrafía, la parte inferior del estrato B-I de la fase B1 pasó a denominarse fase $\mathrm{A} / \mathrm{B} 1$, y procedente de la parte inferior de una fosa, la $\mathrm{n}^{\circ} \mathrm{VIII}$, se obtuvo B-4.178 $800 \pm 50$ a.C. (cal. 897-870 A.C.) (Schubart 1983: 130 y 1985: 167).

De la fase B1, concretamente del área de los talleres metalúrgicos de trabajo del hierro, el horno no 3 aportó B-4.180 620 \pm 50 a.C. (cal. 790 A.C.). Otra determinación procedente del horno no 4, B-4181 $1210 \pm 50$ a.C. (cal. 1419 A.C.), resulta rechazable, aunque Aubet (1994: 320) atribuye al poblado precedente del "Cobre/Bronce prefenicio". En teoría, la determinación corresponde al Bronce Final, pero no está claro que las cerámicas documentadas (Schubart 1985: 166, fig. 14) no correspondan a contextos con cerámicas a torno fenicias, dado que no se individualiza en la secuencia un estrato del Bronce Final y obviamente la determinación no puede ser asignada al Calcolítico. Es interesante señalar que Schubart (1983: 130 y 1985: 167) considera igualmente demasiado reciente el 620 a.C. (790 A.C.) ya que a su juicio debería indicar la primera mitad del s. VIII, ca. $800-750$ a.C.

Finalmente de la fase B2, procede B-4175 610 \pm 50 a.C. (cal. 785 A.C.) (Ib. 1983: 130 y 1985: 167), que supone un cambio general en las estructuras de la planta del poblado, y que debería distanciarse desde un punto de vista cronológico.

En teoría, tal como indica Aubet (1994: 323), de acuerdo con Morro de Mezquitilla los fenicios se instalaron en Málaga entre el 894-835 a.C., o más correctamente entre el 999-807 A.C., pero se trata aún de una única determinación procedente de una fosa, de carbón (Schubart 1985: 167; como madera en Aubet (1994:325)) y conviene cierta prudencia, aunque obviamente de momento la fecha calibrada señala el primer cuarto 
del s. IX A.C., el contexto cerámico es el adecuado y se ve apoyada por la datación más antigua de Acinipo del 820 a.C. (910 A.C.).

\section{Córdoba}

\section{Cerro del Castillo (Monturque)}

En la fase III o estrato VIII del Cerro del Castillo (vide supra), que López Palomo (1993) asigna al Bronce Medio, niveles 27-23, se advierte una marcada continuidad, salvo la construcción de una habitación de planta ortogonal y muros rectos (Ib. 1993: fig. 113), que posteriormente se incendia, constituyendo los niveles 25-23 etapas de colmatación.

L.A. López Palomo (1993: 298) pretende, no sin cierta lógica, fechar esta fase con el carbón procedente del nivel 42, estrato XI, ya que obviamente el carbón tiene que proceder de algún nivel, concluyendo que "esta cronología debe aplicarse al horizonte III". Sin embargo, al tratarse de una muestra obtenida con mezcla de carbones quizás de varios niveles resulta una estrategia incorrecta. Por otra parte, la misma determinación 1440 a.C. (1680 A.C.) señala un momento de práctico final del Bronce Medio y tránsito al Bronce Final, que no se articula bien con la continuidad en los niveles 27-26 con el estrato IX del Bronce Inicial, y la posterior deposición de varios niveles de colmatación, del 25 al 23. Cabe, consecuentemente, pensar en la presencia de un hiatus en el poblado, o al menos en el área del sondeo, que incluso se insinuaba en la primera interpretación de la estratigrafía (Ib. 1990: 189) cuando agrupó los estratos IX y VIII en la fase II y no se contemplaba la presencia de una fase avanzada del Bronce Inicial ni tampoco del Bronce Medio.

La fase III-IV o estrato VII, niveles 22-18, inicialmente considerada como Bronce Tardío (Ib. 1990) y posteriormente Bronce Medio (Ib. 1993), es interpretada como un momento en que se produce un desplazamiento del hábitat hacia otros puntos del cerro mientras el área del sondeo sería utilizado como un "cementerio de túmulos de piedra". Objetivamente, la información disponible (Ib. 1993: 111) sólo señala para el nivel 22 un enterramiento infantil en posición fetal, con un ajuar que incluía un collar de conchas y piedras de color verde, pero cuyo túmulo, dados los $14 \mathrm{~cm}$ de potencia del nivel 22 , difícilmente puede corresponder a más de una piedra de tamaño medio. Del "plano de asiento" de este enterramiento se tomó la muestra UGRA-308 1090 \pm 90 a.C. (cal. 1290-1270 A.C.) que marca un momento del Bronce Final IIA, pero si tomamos los intervalos mínimo y máximo de la calibración 1506-1004 A.C., los mismos se extienden entre el Bronce Final I e inicios del Bronce Final III, pero no al Bronce Medio.

Tras el nivel 21 que marca una separación en la "necrópolis", en el nivel 20 (Ib. 1993: 98) encontramos un nuevo enterramiento de un adulto en decúbito supino con un brazalete de metal como ajuar y quizás algunos fragmentos cerámicos, sobre el que se superponía una acumulación de piedras en forma de túmulo.

A continuación los niveles 19 y 18 corresponderían a "tierra rojiza, que acarreó material heterogéneo" y "sellaron el cementerio terraplenando las tumbas para construir un poblado" lo que explicaría que en dicho relleno "coexisten facies cerámicas distintas, con un amplio marco cronológico" (Ib. 1993: 299).

Este estrato VII ha sido interpretado por J.F. Murillo (1995: 195) como una necrópolis del Bronce Medio, mientras los niveles superiores 19 y 18 marcarían una transición al Bronce Final, defendiendo el mantenimiento del hábitat en las inmediaciones del área del sondeo "en contra de los sostenido por el excavador". Sin embargo López Palomo (1993: 298) en sus conclusiones también parece defender que no existe tal hiatus sino un “fenómeno microespacial" por "el desplazamiento de la población hacia otras áreas" del poblado.

La cuestión formal a tener en cuenta, si los niveles 19 y 18 son de colmatación artificial para la ocupación de la fase IV o estrato VI, es que habría sido adecuado marcar el comienzo de la fase a partir de tales niveles, 
ya que el relleno habría que fecharlo en un momento vinculado al estrato VI, si tenemos en cuenta la presencia entre las cerámicas de "cazuelas" con decoración bruñida.

Finalmente, la determinación obtenida del nivel 22 marca en sus intervalos máximo y mínimo un momento del Bronce Final I-III, que podría definirse en su intervalo mínimo como Bronce Tardío tal como hizo inicialmente López Palomo (1990), pero no Bronce Medio como después han propuesto López Palomo (1993) y Murillo (1995) para el nivel, salvo que formalmente se rechace la datación, tal como hace Murillo (1995: 193), pero no López Palomo (1993: 299).

La fase IV o estrato VI, niveles 17-13, es la última que aporta una determinación por el $\mathrm{C}^{14}$. De una vivienda de planta ortogonal, se tomó una muestra en su esquina norte, correspondiente al incendio de su techumbre que marca el nivel 13 o último del estrato, UGRA-311 1240 \pm 90 a.C. (cal. 1440 A.C.), que $a$ priori correspondería a un momento del Bronce Final IB, y si tomamos sus intervalos mínimo y máximo (1674-1226 A.C.) abarcaría entre finales del Bronce Medio y el Bronce Final IIA, banda temporal más antigua que la determinación obtenida en el nivel 22. No obstante, ya el mismo López Palomo (1993: 300, 302), aunque acepta la determinación como una contradicción aparente escogiendo el intervalo más reciente de la calibración, admite que aún así "no podemos aceptar esta cronología para todo el registro (...) sino únicamente para los materiales arcaizantes" dada la mayoritaria presencia de cerámica con decoración bruñida, algo más del $50 \%$.

La impresión general que se obtiene de este contradictorio conjunto es que si tomamos sus intervalos medios, ninguna se corresponde adecuadamente con el contexto que aparentemente deberían datar. Sería conveniente realizar algunas nuevas determinaciones, como los huesos de los enterramientos del estrato VII y el depósito de trigo del estrato VI, las cuales ayuden a dar mayor solidez al registro artefactual recuperado en esta secuencia que manifiesta notables hiatus ocupacionales.

\section{Llanete de los Moros (Montoro)}

El poblado del Llanete de los Moros, de unas 10 Ha de extensión (Murillo 1995: 221), que actualmente tiene un Centro de Formación Profesional en su cima, tras diversos hallazgos aislados y una prospección superficial a fines de los años setenta (Martín de la Cruz 1978-79) donde se presentó escasas cerámicas del Bronce Final, se ha venido excavando ininterrumpidamente entre 1980 y 1984 . En la campaña de 1980-81 se abrirán en la primera terraza o superior, al sureste del poblado, los cortes R-1, R-2 y R-3, finalizándose este último en la campaña de 1985. En 1987 se realizará una excavación de urgencia (Martín de la Cruz et alii 1990) y posteriormente excavaciones sistemáticas en 1985 y 1990 (Martín de la Cruz 1987b; Martín de la Cruz et alii 1990).

En el corte R.1, de 8 x 4 m y profundidad máxima de $4,5 \mathrm{~m}$, son los estratos IIIA y IIIb de ca. $1 \mathrm{~m}$ de potencia entre ambos, donde exclusivamente se ha localizado cerámica tipo Cogotas I, procediendo del estrato IIIa, infrapuesto al IIIb a 4,4 m, UGRA-190 980 \pm 110 a.C. (1120 A.C.) (González Gómez et alii 1986: 1203; Martín de la Cruz et alii 1987: 206) y del estrato IIIb, a 3,1 m de profundidad, UGRA-159 1030 \pm 130 a.C. (cal. 1250-1200 A.C.) (González Gómez et alii 1986: 1203; Martín de la Cruz y Montes 1986: 491). Esta inversión cronológica de las determinaciones resulta algo menos marcada si tomamos los intervalos máximos y mínimos de su calibración que señalan entre un 1513-837 A.C. y 1415-831 A.C., que marcan una banda entre el Bronce Final IB hasta el Bronce Final IIIB. En todo caso, sería conveniente volver a fechar muestras de ambos niveles para contrastar si realmente existe algún tipo de filtraciones desde el nivel IIIb hacia el nivel IIIa y despejar dudas sobre el registro artefactual que Martín de la Cruz et alii (1987: 207) divide en una fase del Bronce Final I para el nivel IIIA y otra del Bronce Final II para el IIIb. 
El corte B1.2, también de la primera terraza, de $4 \times 4 \mathrm{~m}$ y profundidad máxima de $2 \mathrm{~m}$, presenta cerámicas tipo Cogotas I en el estrato I de 0,10-0,20 m de potencia, obteniéndose la determinación CSIC-624 950 550 a.C. (cal. 1045 A.C.) (Martín de la Cruz y Montes 1986: 494) donde se documentó una "cazuela" tipo Cogotas I y un soporte liso (Martín de la Cruz y Baquedano 1987: 52 fig. 2, 56 fig. 3).

Próximo al corte R.1, el R.2 de 8 x 4 m y una potencia máxima de $6 \mathrm{~m}$ (Baquedano 1987: 226; Martín de la Cruz y Baquedano 1987) presenta en sus determinaciones una inversión temporal si nos atenemos a la estratigrafía del corte. Del nivel más antiguo datado, el $\mathrm{n}^{\circ}$ 6, procede UGRA-187 960 \pm 120 a.C. (cal. 1110-1060 A.C.) (González Gómez et alii 1986: 1203; Martín de la Cruz y Baquedano 1987: 52, 54). Del nivel 8 , UGRA- $186760 \pm 250$ a.C. (cal. 830 A.C.) sobre semillas, cuya desviación de \pm 250 años deriva de la escasez de muestra remitida al laboratorio (González Gómez et alii 1986: 1203; Martín de la Cruz y Baquedano 1987: 53-54, 56). Finalmente, existen dos fosas realizadas en el nivel 8, una ovoide, realizada cuando se estaba finalizando el nivel 8 o ya finalizado, y otra rectangular, de las cuales proceden a $4,1 \mathrm{~m}$ de profundidad UGRA-183 1130 \pm 90 a.C. (cal. 1380-1320 A.C.) y a 3,9 $\mathrm{m}$ de profundidad UGRA-160 1050 \pm 100 a.C. (cal. 1260-1220 A.C.) que consideran demasiado antiguas, no debiendo ambas sobrepasar el 900 a.C. (González Gómez et alii 1986: 1203; Martín de la Cruz y Baquedano 1987: 53, 55).

Para tratar de buscar una explicación a esta secuencia es preciso tener en cuenta que la fosa o estructura ovoide (Baquedano 1987: 226-227, fig. 2), de la probablemente proceden las muestras UGRA 183 y 160 , perfora el corte R. 2 desde el nivel 8 hasta el nivel 3, atravesando claramente el nivel 6 de acuerdo con el perfil aportado. Ello explica que la profundidad de UGRA-160 (nivel 8-fosa) y UGRA-187 (nivel 6) posean la misma cota de 3,9 m, y que incluso UGRA 183 (nivel 8-fosa) proceda de aún mayor profundidad, 4,1 m y es coherente que UGRA-186 (nivel 8), el más reciente, tenga una cota de $3,4 \mathrm{~m}$. Si descartamos esta última, por su elevada desviación estadística, una posible ordenación de las determinaciones sería 1380-1320 A.C. 1260-1220 A.C. y 1110-1060 A.C. donde se incorporarían como intrusiones carbones y semillas de los estratos que fueron perforados por la fosa. Así pues, la única determinación que parece proceder de un contexto más seguro sería la del nivel 6 con cerámica decoradas tipo Cogotas I fechables hacia el 1110-1060 A.C. que nos marca un momento del Bronce Final 2 o IIC.

Finalmente, dentro del corte R-3, se documentó en una fosa (Martín de la Cruz 1988), que correspondería al nivel III, que corta el nivel precedente o nivel II. Dicha fosa se divide en 4 subniveles, que desconocemos si se tratan de niveles naturales, que parece presumible en la subdivisión, o de alzadas artificiales durante la excavación, ya que no se presenta, los subniveles divididos en un perfil dibujado.

El primero de los subniveles, III.1, muestra cerámicas con decoraciones excisas y de boquique, III.2 un fragmento micénico acompaña a boquique, en III. 3 continua el boquique y en III.4, junto a dicha cerámica decorada aparece el segundo fragmento micénico. Del nivel IV sólo disponemos de una pieza dibujada decorada incisa presumiblemente tipo "cogotas", sobre el que se dispone un derrumbe o nivel V. Las determinaciones corresponderían a CSIC-795 1110 \pm 60 a.C. (cal. 1310 A.C.) para "el nivel en el que aparecieron las cerámicas" y CSIC-794 1070 \pm 60 a.C. (cal. 1260 A.C.) para el nivel "inmediatamente encima dentro del estrato III" (Martín de la Cruz y Perlines 1993: 337). Aparentemente, la primera correspondería al III. 2 y la segunda al III.3, pero ello implicaría que una cerámica micénica correspondería a c. 1310 A.C. y la otra sería posterior al menos de c. 1260 A.C., ya que está en el subnivel III.4, y sobre éste no existen más subniveles. En todo caso, ambas fechas se corresponden bien con el Heládico Final IIIA2 o IIIB, c. 13751225 A.C., a los que tipológicamente se asignan las piezas.

Es importante recalcar que aunque Martín de la Cruz (1984-85: 213) señala la presencia de "fragmentos de campaniforme en el estrato III del corte R-3, asociados en algún caso con las cerámicas micénicas", si nos atenemos a los dibujos publicados, en ningún caso se presenta una auténtica cerámica campaniforme, tratándose de cerámicas decoradas Cogotas I. La única excepción en las fig. 2 y 3 es la pieza 2/66, asignable 
a una cazuela campaniforme, y procede del nivel Ic, que cabe vincular a la cabaña con campaniformes incisos documentada en los niveles Ia y Ib del corte (Martín de la Cruz 1989: 124).

Cabe reseñar que de una determinación UGRA-175 940 \pm 140 a.C. (cal. 1030 A.C.), obtenida a 3,9 m de profundidad, carecemos de cualquier dato contextual sobre la misma.

Los problemas de inversiones en las determinaciones han llevado a varios autores a descartar el conjunto de estas dataciones (Belén et alii 1992: 67; Murillo 1995: 313), sin embargo, creemos que pueden hacerse algunas excepciones.

En este sentido, contamos con determinaciones que fechan contextos tipo Cogotas I en el 1310 A.C., 1260 A.C., $1110-1060$ A.C. y 1045 A.C., o en la cronología tradicional 1110 a.C. 1070 a.C., 1045 a.C. y 960 a.C., que resultan a nuestro juicio coherentes con las obtenidas en Cuesta del Negro (Purullena, Granada) que dan incluso fechas más antiguas (Molina 1978: 170; Ambers et alii 1991: 65; Mederos e.p.).

En conclusión, la serie del Llanete de los Moros, que sorprendentemente ha sido considerada propia del Bronce Tardío del Sureste (Lull et alii 1992: 267), presenta notables problemas de articulación interna en relación con la estratigrafía de los cortes, y un ejemplo de ello lo refleja la propia valoración de su director sobre las determinaciones del laboratorio de Granada (González Gómez et alii 1986: 1203) cuando comenta que no eran edades esperadas para las muestras. No obstante, nuevas dataciones obtenidas en puntos de discrepancia, caso de la superposición del corte R-1, ayudarían a clarificar su secuencia.

\section{Sevilla}

\section{Setefilla (Lora del Río)}

Los trabajos de campo en el yacimiento de Setefilla comienzan en el área de la necrópolis, excavándose los túmulos A y B (Aubet 1975 y 1978). A partir de 1976 empezaron a desarrollarse excavaciones en el poblado dirigidas por $M^{a}$.E. Aubet, $O$. Arteaga y $M^{a}$.R. Serna, abriéndose el corte 1 , en el cual aparentemente en su base se localizó un doble paramento de muralla de más de $5 \mathrm{~m}$ de anchura, con cronología imprecisa, pero que Aubet (1989: 300-301) correlaciona con la fase IIb, estrato XIIa del Corte 3 de 1979.

En la campaña de 1979, dirigida por Aubet y Serna, se abrirán dos nuevos cortes, el no 2 , que presenta un paramento de muralla con un bastión circular que atribuyen a la fase I, estrato XIV, y el corte 3 que ha aportado la estratigrafía básica del poblado.

En este último, su nivel XV cuenta con un triple enterramiento en una fosa con dos hombres y un joven, aparentemente al exterior de una cabaña, puesto que no hay evidencias de estructuras habitaciones superpuestas a la sepultura. Este nivel parece no ser homogéneo, puesto que el nivel XIV a veces también se dispone sobre la roca virgen.

Según Martín de la Cruz et alii (1987: 204) la sepultura se excavaría en los comienzos del estrato XIII perforando el derrumbe de lajas que sellaban el nivel de incendio del estrato XIV que formaría un mismo estrato con el XV, lo que vendría ratificado por la presencia de materiales tipo Cogotas I (Martín de la Cruz 1989: 132, 129 nota 19).

'Una observación detallada de la información disponible creemos que confirma parte de esta apreciación. En la lámina Xb se aprecia el nivel superior del derrumbe del estrato XIV y la "estructura" de la sepultura, compuesta por piedras más pequeñas y dislocadas, con diferente orientación que el derrumbe, en la parte inferior (sur) de la foto. Si posteriormente nos remitimos a la planta del nivel XIV (Aubet et alii 1983: 46, fig. 13) se aprecia en el dibujo, en su parte superior (norte), que las piedras del derrumbe son las mismas que las de la foto. Un dato adicional es que la profundidad de las piedras de la planta del derrumbe, $c a$. 7,07-7,10 m coinciden con la piedra mayor dispuesta sobre la sepultura, 7,07 m. 
Una explicación posible es que el pie de foto de la lámina $\mathrm{Xb}$ lo que realmente esté señalando es el punto en el que se levantó la planta de dicho nivel, y no necesariamente el nivel superior, lo que creemos confirma el dibujo. En todo caso, a nivel estratigráfico parece que existe una relativa coetaneidad entre los estratos XV y XIV. Presuponer que la sepultura procede de los inicios del nivel XIII resulta más aventurado, aunque se tratase del nivel superior del estrato XIV, ya que no hay documentación de secciones que lo confirmen, pero obviamente entre el nivel superior del XIV y el nivel inferior del XIII no debió existir mucha separación.

En todo caso, como explicación de esta relativa confusión entre el nivel superior y el nivel de la planta del estrato XIV habría que tener en cuenta (Aubet et alii 1983: 44-45) las dificultades de trabajo a ca. $6 \mathrm{~m}$ de profundidad, un espacio de menos de $2 \mathrm{~m}$ de largo, encontrándose piedras de hasta $0,60 \mathrm{~m}$ de longitud y un derrumbe en sectores con una potencia de $0,70 \mathrm{~m}$, que no facilitaría una buena documentación en planta, donde levantar una piedra puede implicar $c a .20-40 \mathrm{~cm}$ de profundidad.

Por otra parte, el ajuar de la sepultura con estoque, alabarda y un puñal evolucionado, Martín de la Cruz et alii (1987: 204) lo consideran propio de los inicios del Bronce Tardío. Una atribución ligeramente más antigua es apuntada por Pellicer (1989: 166), para quien resulta típico de un Bronce Pleno avanzado.

La inusual asociación de un estoque y una alabarda, coexistencia ausente en el Sureste, no facilita las cosas. En principio la alabarda, diferente a las argáricas por su doble nervio central, no debería ser más reciente de un momento inicial del Bronce Medio si tomamos al Sureste como referente. El estoque, por el contrario, abarcaría desde finales del Bronce Inicial hasta, al menos, finales del Bronce Medio. No obstante, aunque Martín de la Cruz et alii (1987: 204) consideran que "la cronología que se ajustaría más a la fecha real (...) la proporcionarían los elementos más modernos (...) sobre todo el recipiente cerámico", para nosotros la clave está en si podemos admitir una perduración de las alabardas hasta momentos avanzados del Bronce Medio. En este sentido, nosotros creemos que es posible que sí, porque tanto el estoque como la alabarda responden a patrones metalúrgicos atlánticos y no a los de Sureste. Téngase en cuenta que el estoque (Aubet et alii 1983: 63, fig. 21/38) responde a un modelo de 4 remaches en disposición romboidal, número de remaches que tendrá continuidad, con lógicos cambios, en las espadas tipo Rosnoën.

Si ạdemás tomamos las dos dataciones del poblado (Aubet y Serna 1981:226; Aubet 1981: 129) I-11.070 1570 \pm 95 a.C. (cal. 1880-1790 A.C.) del nivel XIV, e I-11.069 1520 \pm 95 a.C. (cal. 1750 A.C.) del nivel XIII, al tratarse de muestras de madera probablemente nos están datando momentos más antiguos que el contexto arqueológico al que a priori deberían pertenecer y que, en teoría, por las fechas que ofrecen y los rangos de la calibración, deberían ser del Bronce Medio 2, y podrían encuadrarse en un momento de tránsito entre el Bronce Medio y el Bronce Final 1 o IA hasta ca. 1625 A.C., esto es, que fuesen al menos unos 125 años más recientes.

De la muestra obtenida del nivel XIV, procedente del nivel de incendio de las estructuras de habitación, se ha planteado (Aubet et alii 1983:48) que serviría como un terminus ante quem para fechar el enterramiento del nivel XV. Sin embargo; debe tenerse en cuenta que carecemos de una determinación concreta del mismo, por ejemplo de los huesos, que clarifique el grado de proximidad temporal entre los niveles XV y XIV, y quizás la propia fecha del 1570 à.C: (1880-1790 A.C.) del nivel XIV, tal como hemos comentado, resulte más antigua de lo que realmente es.

Si observamos el registro artefactual del nivęl XV sólo caben dos alternativas, admitir una periodización más reciente o suponer algún tipo de intrusión desde los estratos superiores. La presencia de una "cazuela" con carena alta (Ib. 1983: 53, fig. 15/4), un borde con decoración incisa al exterior e interior (Ib. 1983: 54, fig. 16/10) y un borde de "cazuela" con asa realzada que advierten no han dibujado (Ib. 1983: 56), son cerámicas que tal como también destacan Martín de la Cruz et alii (1987: 204) nos remiten al menos a inicios del Bronce Final. Además, el supuesto brazal de arquero (Aubet et alii 1983: 54, fig. 16/13) es discutible, ya que sólo cuenta con un agujero central, y no debè tomarse como un índice de antigüedad. 
Por otra parte, en el nivel XIV nos seguimos encontrando con artefactos aparentemente anómalos, salvo que se hayan producido puntuales intrusiones no detectadas o que realmente nos encontremos en un momento de inicios del Bronce Final I, como un fragmento posible de Cogotas con carena alta y decoración impresa e incisa (Ib. 1983: 58, fig. 18/23) o quizás el soporte (Ib. 1983: 59, fig. 19/31).

La determinación del nivel XIII resulta también compleja, estrato que según Pellicer (1989: 166) se encuentra "bastante removido (...) por las fosas de cimentación de los gruesos muros que cruzan el corte 3". En principio, es importante indicar que la datación proviene de cerca de la base, con lo que se vincularía a los momentos finales del nivel XIV, y al proceder de madera cabe presuponerle igualmente mayor antigüedad a la muestra. El nivel resulta anómalo, pues pese a contar con más de $1 \mathrm{~m}$ de potencia, se habla (Aubet $\boldsymbol{e t}$ alii 1983: 70) de "un suelo de habitación con restos de construcciones de piedra", pero "no aparecieron hallazgos arqueológicos en relación con el nivel de habitación de base". Sobre el mismo, se producirían algunos aportes de artefactos procedentes de áreas de habitación situadas en las inmediaciones. Sólo un borde, con decoración incisa cerca del borde (Ib. 1983: 74, fig. 25/71), recuerda a Cogotas I, pero conviene adoptar una actitud prudente antes que proclamar la antiguiedad de dicha decoración en Andalucía (Delibes y Fernández-Miranda 1986-87:24), cuando quizás la muestra no sea la adecuada, y quizás por ello recientemente esa decoración ha sido considerada propia de las incisas tipo Cogeces (Delibes y Romero 1992: 234).

J.L. Escacena considera que, pese a la antigüedad de la determinación, las cuales provocan "dudas" pero "no pueden refutarse" de momento (Belén et alii 1992: 68), indican un momento de tránsito del Bronce Medio al Bronce Final para el nivel XIII, mayor modernidad que compartimos pues difícilmente puede aceptarse una fecha de finales de un momento avanzado del Bronce Medio en un contexto con cerámicas pintadas a sólo $20 \mathrm{~cm}$ por encima del "piso" sin artefactos, cazuelas bruñidas al interior, soportes, etc. No cabe descartar que se trate de un estrato de colmatación natural tras el final de la ocupación en ese área, sobre el que se superpuso en un momento determinado un relleno antes de levantar el primer pavimento de habitación de la fase IIB, lo que justificaría la visión distorsionada del registro cerámico.

Esta conclusión implicaría lógicamente un hiatus, que también sugieren Belén et alii (1992: 68) al apuntar una repoblación en el S. IX a.C., aunque por nuestra parte, sin entrar a valorar esa nueva cronología, desconocemos si el hiatus podemos hacerlo extensivo a todo el poblado o sólo al área puntual del sondeo.

Por consiguiente, creemos que de admitirse un tránsito del Bronce Medio al Bronce Final para los niveles XV y XIV se podría dar una explicación adecuada a la presencia de determinadas cerámicas de tipo Cogotas I, para lo cual habría que aceptar que las determinaciones, al ser sobre madera, nos están indicado una fase más antigua, y además que pudo haberse producido en Andalucía Occidental la pervivencia de alabardas hasta finales del Bronce Medio, que por otra parte quizás también apuntan otros modelos como las alabardas tipo Montejícar.

En todo caso, debe tomarse como una valoración provisional hasta que en un futuro se realice una o varias dataciones de los huesos de la sepultura, las cuales consolidarían con bases más firmes esta interesante estratigrafía.

\section{Cádiz}

Monte Berrueco (Medina Sidonia)

En la parte superior del estrato III del Monte Berrueco (vide supra) se obtuvo I-? 1360 \pm 80 a.C. (cal. 1600-1530 A.C.) que cabe asignar al Bronce Final 1A, contextos tradicionalmente asignados al Bronce Tardío, aunque inicialmente sus excavadores lo consideraron Bronce Medio (Escacena y Frutos 1985; Pellicer 1989: 160). Por entonces, el equivalente al Bronce Tardío del Sureste vendría a estar representado para 
ellos (Escacena y Frutos 1985: 36) en el estrato IV, que consideran una etapa de tránsito entre el Bronce Medio y el Bronce Final. No obstante, en una aportación posterior (Belén et alii 1992: 70), Escacena reconoce que esta determinación no resulta discordante con el Bronce Tardío e incluso un fragmento cerámico inciso relleno de puntos (Escacena y Frutos 1985: 34, 69, fig. 23/145) responde a este patrón como ya en su momento destacaron. Determinados artefactos, caso de los cuencos con carena alta próxima al borde, apoyarían igualmente esta cronología de inicios del Bronce Final 1A.

Futuros trabajos en este poblado creemos que servirían de contraste a la estratigrafía de Fuente Álamo para interpretar cómo se produjo el inicio del Bronce Final en Andalucía Occidental.

\section{Loma del Puerto (Chiclana de la Frontera)}

En la finca costera de la Loma del Puerto, a raíz de la realización de obras de infraestructura de una urbanización se efectuaron prospecciones en 1991 y excavaciones de urgencia en 1992 dirigidas por F. Giles en una necrópolis sobre una pequeña elevación situada a $400 \mathrm{~m}$ de la playa.

En la necrópolis, situada en la ladera sureste, se excavaron seis sepulturas en las margas terciarias, realizándose siempre dos cubetas interconectadas descendentes, en la cual la primera o B, actúa como espacio de acceso, el espacio intermedio entre ambas se cierra con lajas de arenisca dispuestas verticalmente, y mientras en el segundo rehundimiento o A se realizaba un enterramiento colectivo, que al menos en la sep. 6 fue de cinco individuos (Giles et alii 1993-94: 47, 51 fig. 2-3).

Dada la ausencia de un ajuar significativo, caso de la sep. 6 donde se documentó un borde de un cuenco, un adorno de cobre o bronce y restos malacológicos, el principal elemento de encuadre es la datación de los huesos de dicha sepultura, UBAR-346 990 \pm 90 a.C. (cal. 1120 A.C.) (Ib. 1993-94: 46), que nos remite a un momento final del Bronce Final $2 \mathrm{C}$ o IIC, aunque sus autores prefieren correlacionarla con el nivel III de Monte Berrueco (vide supra), asignable a comienzos del Bronce Final IA. Sería conveniente, por tanto, quizás alguna otra datación para precisar más el encuadre temporal de esta necrópolis.

\section{Huelva}

\section{Chinflón (Zalamea la Real)}

El poblado de Chinflón, situado en la cumbre de un cerro que presenta afloramientos de malaquita, fue excavado inicialmente por B. Rothenberg en 1976, quien realizó un pequeño sondeo en el poblado pero no pudo recuperar apenas cerámicas que definieran con precisión la cronología del mismo. En sus inmediaciones se sitúan varios sepulcros megalíticos del Calcolítico.

En 1978 se realizaron dos campañas simultáneas, una en el poblado dirigida por M. Pellicer y V. Hurtado (1980), y otra en dos de las minas de cobre situadas en sus inmediaciones por A. Blanco Freijeiro, B. Rothenberg y P. Andrews, que fueron continuadas en 1979 y 1980.

De acuerdo con los resultados obtenidos en unos $110 \mathrm{~m}^{2}$ de la excavación en el poblado, apenas se documentó estratigrafía salvo una capa superficial de unos $10 \mathrm{~cm}$ de media y un segundo nivel con materiales erosionados de unos $20 \mathrm{~cm}$, destacando la presencia de cuatro fragmentos cerámicos del Bronce Final, junto a escorias de cobre y martillos de minero con cierta abundancia.

Por otra parte, procedente de la estratigrafía del mismo, contamos del nivel 2 BM-1528 700 \pm 60 a.C. (cal. 810 A.C.), nivel 3 BM-1529 1370 \pm 130 a.C. (cal. 1610-1540 A.C.) y nivel 4 BM-1600 570 \pm 210 a.C. (cal. 770 A.C.), procedentes de los cuadrados contiguos A1 y B1 (Burleigh et alii 1982: 252; Rothenberg 
y Blanco 1980: 44 fig. 2,53), lo que implica algún tipo de inversión estratigráfica por la erosión o filtraciones de partículas de carbón.

De la mina 3, nivel 9 o base del pozo 3B3, estrato que consideran se depositó por causas naturales, aparecieron varios troncos de madera, tal vez parte de una escala de los cuales procede BM-1599 880 \pm 50 a.C. (cal. 987-944 A.C.) (Burleigh et alii 1982: 252; Rothenberg y Blanco 1980: 48 fig. 5, 49, 53), muestra de la que debe tenerse en cuenta que procede de un madero que está indicando quizás un momento más antiguo que el de su verdadera explotación. No obstante, Rothenberg y Blanco (1980: 49, fig. 6/2) señalan que en lo alto de la mina, entre los pozos 3B3 y 3B4 apareció un cuenco calcolítico.

Durante la campaña de 1979 se reanudaron las excavaciones en dicha mina, terminándose de excavar el pozo 3B4 del que procede un vaso de fondo plano (Ib. 1980: 49, fig. 6/1) también aparentemente Calcolítico según los autores. Sin embargo, ambas cerámicas no presentan formas definitorias para atribuirles una cronología definida.

Finalmente, de otras dos determinaciones desconocemos si provienen del poblado o de la mina, BM-1601 $570 \pm 210$ a.C. (cal. 770 A.C.) y BM-2064R 400 \pm 100 a.C. (cal. 400 A.C.), inicialmente publicada como BM-2064 490 \pm 50 a.C, pero que resultó afectada por el error del laboratorio del British Museum (Burleigh et alii 1982: 252; Rothenberg y Blanco 1980: 53; Bowman et alii 1990: 77). Esta última, en teoría (Burleigh et alii 1984: 71), provendría de una mina del área de Chinflón, ya que fue tomada a $15 \mathrm{~m}$ de profundidad en 1981 a partir de un tronco de madera de erica arborae, de la cual se extrajo la celulosa para muestrearla, con lo que BM-2064R aparentemente tendría similar procedencia al contarse aún con suficiente muestra para datarla nuevamente.

En la misma serie se incluye una muestra tomada en la campaña de 1979, de la que no disponemos de información, procedente de la "Pisotilla", cuyas coordenadas que se ofrecen son las mismas que para Chinflón. A priori, si nos atenemos a la misma, BM-1603 1910 a.C. (cal. 2320 A.C.) (Burleigh et alii 1982: 252) nos encontraríamos en un momento de comienzos del Bronce Inicial. Sin embargo, la falta de cualquier dato contextual impide su valoración. Además, debe tomarse con bastante precaución ya que los intervalos de calibración son espectacularmente amplios, marcando desde el 2131 a 2077 A.C. y 2047 A.C. hasta el 1955 D.C.

Ría de Huelva (Huelva)

El depósito de Huelva cuenta con una notable serie de dataciones (Almagro-Gorbea 1977: 524-525), procedentes de fragmentos de astiles de madera en el interior de los regatones metálicos de las lanzas. CSIC$202880 \pm 70$ a.C. (cal. $987-944$ A.C.), CSIC-203 860 \pm 70 a.C. (cal. $976-935$ A.C.), CSIC-206 $870 \pm 70$ a.C. (cal. 976-935 A.C.), CSIC-207 870 \pm 70 a.C. (cal. 976-935 A.C.), CSIC-205 860 \pm 70 a.C. (cal. 927 A.C.) y CSIC-204 850 \pm 70 a.C. (cal. 922 A.C.), los cuales marcan valores medios entre ca. 880-850 a.C. o 987-922 A.C. No obstante, debería tenerse cierta precaución por si pudo haberse producido la reutilización de astiles antiguos, lo que implicaría fechas aún más recientes. Sin embargo, la duda puede minimizarse dada la homogeneidad de esta serie de determinaciones.

Debe advertirse, pese a todo, que algunos autores han apuntado la presencia en el depósito de una espada de espiga tipo Rixheim-Monza (Almagro Basch 1958; Harrison 1974-75: 230), asignable al Bronce Final I, con quizás alguna prolongación, debiendo agregarse una lanza con perforaciones basales teóricamente del Bronce Final II (Almagro Basch 1940: lám. IV/6 y 1958: no 140), espadas de lengua de carpa tipo Huelva (Almagro Basch 1940: lám. I-II y 1958), o incluso aparentemente lanzas tipo Venat (Ruiz-Gálvez 1984: 282-283), los cuales nos indican que no se puede considerar un depósito cronológicamente homogéneo, aunque la mayoría de los artefactos marcan un momento de transición entre la metalurgia tipo Huelva, del 
Bronce Final IIIA, con la metalurgia tipo Venat, representadas por las puntas de lanza, que señalarían el inicio del Bronce Final IIIB.

\section{ANÁLISIS}

Tabla 1. Número de dataciones por quinquenios con su distribución provincial en Andalucía Occidental

\begin{tabular}{|c|c|c|c|c|c|c|}
\hline Fases & Total y \% & Málaga & Córdoba & Sevilla & Cádiz & Huelva \\
\hline $1970-74$ & 12 & 1 & 11 & - & - & - \\
\hline $1975-79$ & 6 & - & -- & - & - & 6 \\
\hline $1980-84$ & 24 & 5 & - & 10 & 3 & 6 \\
\hline $1985-89$ & 35 & 22 & 8 & 2 & 1 & 2 \\
\hline $1990-94$ & 23 & 5 & 6 & 4 & 6 & 2 \\
\hline $\begin{array}{c}\text { Total y \% } \\
\text { provincial }\end{array}$ & 100 & 33 & 25 & 16 & 10 & 16 \\
\hline
\end{tabular}

En la tabla 1 hemos tratado de sintetizar la progresión en la publicación de dataciones por $\mathrm{C}^{14}$ por provincias en Andalucía Occidental. Objetivamente, no es hasta el quinquenio 1980-84 cuando se aprecia una investigación más equilibrada, si tenemos en cuenta que las series precedentes entre 1970-79 proceden exclusivamente de tres yacimientos: Cueva de los Murciélagos (11), Nerja (1) y el depósito de la Ría de Huelva (6).

El máximo se alcanza en el periodo $1985-89$, un $35 \%$, que podría a primera vista interpretarse como fruto del traspaso de competencias arqueológicas a la Junta de Andalucía desde 1984, y la reanudación de las actuaciones de campo en 1985 , pero se trata de una impresión falsa ya que mayoritariamente proceden de campañas de excavaciones realizadas en la fases precedentes (Nerja, Llanete de los Moros, Palomas, Toro, Berrueco, Papauvas, etc.).

La verdadera sorpresa reside en el último periodo 1990-94, donde se debería ver reflejado el impulso dado el incremento de las excavaciones a partir de 1985 que se han ido recogiendo anualmente en los Anuarios Arqueológicos de Andalucía. La falta de series importantes es altamente significativa, y los máximos están reflejados por un sondeo de 1985, el Castillo de Monturque (4), continuación de la publicación de la serie de la Dehesilla (3) cuya última actuación fue en 1981, y dos excavaciones sistemáticas en El Negrón (3) y Acinipo (3), serie esta última que realmente es mayor porque hay otras tres determinaciones de inicios del contacto con los fenicios.

Un segundo elemento que ratifica esta impresión son los propios Anuarios, donde sólo en dos artículos (Aguayo et alii 1991 y Cruz-Auñón et alii 1992) figuran dataciones novedosas en la bibliografía. La drástica reducción de actuaciones de campo a partir de 1992 en teoría debió acelerar el trabajo de laboratorio y la publicación de informes y memorias. Sin embargo, parece que la falta de vías de financiación precisamente produjo los efectos contrarios.

Paradigmático es el tema de las actuaciones de urgencia, puesto que pese a los masivos volúmenes de informes anuales, en general acaban proporcionado una información bastante pobre porque no se potencia un estudio de laboratorio posterior de estas actuaciones. Resulta casi dramático que sólo contemos con tres dataciones procedentes de las actuaciones en Cádiz, procedentes de Las Viñas (2) 
y Loma del Puerto (1), y ello dentro de los trabajos de un Proyecto de Investigación: "Cuaternario y Geomorfología en Andalucía Occidental".

Tabla 2. Número de dataciones por quinquenio y periodo temporal en Andalucía Occidental.

\begin{tabular}{|c|c|c|c|c|c|}
\hline Fases & Total y \% & Neolítico & Calcolítico & Bronce Inicial y Medio & Bronce Final \\
\hline $1970-74$ & 12 & 12 & - & - & - \\
\hline $1975-79$ & 6 & - & - & - & 6 \\
\hline $1980-84$ & 24 & 12 & 4 & 1 & 7 \\
\hline $1985-89$ & 35 & 19 & 5 & 2 & 9 \\
\hline $1990-94$ & 23 & 7 & 7 & 3 & 6 \\
\hline Total y \% & 100 & 50 & 16 & 6 & 28 \\
\hline
\end{tabular}

Si se observa en la tabla 2 la distribución de las dataciones por grandes periodos temporales y su progresión a través del tiempo, se advierten a simple vista los desequilibrios en la investigación. El Neolítico acapara el $50 \%$ de las dataciones por el número que aportan las cuevas de Nerja, Murciélagos, Dehesilla, Chica de Santiago, Toro y Palomas, muchas de las cuales pueden ser discutibles, pero es evidente que se ha realizado un esfuerzo por secuenciarlas. Lo paradójico es que si nos atenemos a la última campaña de excavaciones realizadas en las mismas, Murciélagos (1969), Chica de Santiago (1980), Dehesilla (1981), Palomas (1982), Nerja (1987) y Toro (1988), no puede decirse que hayan sido en el último decenio particularmente favorecidas en la financiación, y sin embargo, aún en el quinquenio 1990-94, a pesar del progresivo descenso, son las ñáximas en aportar nuevas determinaciones junto al Calcolítico.

El Bronce Final es el segundo periodo que aporta mayor número de dataciones, un $28 \%$, pero si prescindimos del depósito de la Ría de Huelva, las determinaciones procedentes de poblados no comienzan a disponerse hasta inicios de los años ochenta. No obstante, resulta lamentable que si nos atenemos al último quinquenio 1990-94, se aprecia el comienzo de un descenso en las mismas a causa de que son muy pocas las estratigrafías que aportan estas dataciones, y sus últimas actuaciones cada vez se encuentran más lejanas en el tiempo, Setefilla (1979), Berrueco (1982) y Castillo de Monturque (1987), con la excepción del Llanete de los Moros (1990), que con diez dataciones destaca particularmente, y si algunas resultan discutibles, aporta el $36 \%$ de todas las determinaciones para el Bronce Final.

Por el contrario, el Calcolítico y el Bronce Inicial-Medio presentan una progresión positiva que no deja de resultar un espejismo, tanto porque sus porcentajes son los más bajos a nivel global, $16 \%$ para el Calcolítico y $6 \%$ para el Bronce Inicial-Medio, sino también porque las dataciones proceden de muy pocos yacimientos, y por ejemplo en el último quinquenio de 1990-94, sólo son tres en el Calcolítico, Negrón, Viñas y Castillo de Monturque, de los cuales sólo el primero se ha venido excavando con regularidad, y exclusivamente de Acinipo para el Bronce. La polémica sobre el encuadre cronológico de las determinaciones de Setefilla, y su posible inclusión en el Bronce Medio, no afectan a estas conclusiones.

La tabla 3 creemos que refleja fielmente los desequilibrios y dependencias de la investigación en la prehistoria reciente en Andalucía Occidental. Prescindiendo del Neolítico Inicial, sobre cuya atribución en Nerja, Dehesilla y Chica de Santiago ya se aportado nuestra valoración del registro (vide supra), desde la primera mitad de los años setenta se disponía de los primeros referentes cronológicos para la articulación del Neolítico Medio y Final. Paralelamente, el momento final del Bronce Final y el inicio de la colonización fenicia era definidos por el poblado de Toscanos (Málaga) y el depósito de la Ría de Huelva. 
Tabla 3. Primeras dataciones disponibles para cada periodo temporal en Andalucía Occidental

\begin{tabular}{|l|l|l|l|}
\hline Periodo temporal & \multicolumn{1}{|c|}{ Primera datación } & Periodo temporal & \multicolumn{1}{c|}{ Primera datación } \\
\hline Neolítico Inicial & ¿Nerja? & Bronce Inicial & Monte Berrueco, 1985 \\
\hline Neolítico Medio & Murciélagos, 1973 & Bronce Medio & ¿Setefilla, 1981? \\
\hline Neolítico Final & Nerja, 1970 & Bronce Final I & $\begin{array}{l}\text { ¿Setefilla, 1981?; } \\
\text { Monte Berrueco, 1985 }\end{array}$ \\
\hline Calcolítico Inicial & Nerja, 1981 & Bronce Final II & Llanete Moros, 1986 \\
\hline Calcolítico Medio & Cerro de la Cabeza, Valencina, 1980 & Bronce Final III & Ría de Huelva, 1977 \\
\hline Calcolítico Final & Cerro de la Cabeza, Valencina, 1980 & Fenicio & Toscanos, 1970 \\
\hline
\end{tabular}

Ello no sucedió para el Calcolítico y Bronce Final I-II sino hasta inicios de los años ochenta, lo que impondrá una clara dependencia en la investigación de los registros y cronologías de Andalucía Oriental (Mederos e.p.), particularmente de los poblados de Los Millares, Castillejos de Montefrío, Cerro de la Virgen y Cuesta del Negro. Serán en especial estos tres últimos los más utilizados, tanto por su emplazamiento al interior en Granada como por contar, aparte de las dataciones, con secuencias estratigráficas artefactuales bien publicadas que servían de contraste.

La situación más deficiente la refleja el Bronce Inicial y Medio, en clara contradicción con los Entes Arqueológicos "argáricos" de Andalucía Oriental. No será hasta 1985 que contaremos con la primera datación asignable al Bronce Inicial, y ante la falta de referentes locales, como muy bien refleja el título del trabajo de Escacena y Berriatua (1985: 225,238), se interpretará el registro arqueológico del poblado como "testimonio de una probable expansión argárica hacia el oeste" si bien siempre a modo de una "irradiación" cultural.

Este fenómeno ha sido aplicado para el valle medio del Guadalquivir por Martín de la Cruz et alii (1987: 202) quienes hablan de "penetraciones de estos grupos, o la aceptación de sus influjos (...) en gran parte de la cuenca media del Betis", si bien se trataría de una "aculturación muy superficial, más encaminada a la posición de elementos externos de prestigio" (Martín de la Cruz 1989: 126).

En segundo lugar, esta falta de referentes explica la permanente polémica en la atribución cronológica de la sepultura de la Mesa de Setefilla, desde la tácita aceptación de la datación del 1570 a.C. (1880-1790 A.C.) como un terminus ante quem para la sepultura (Aubet et alii 1983: 48), y consecuentemente, de la cronología de las fases iniciales del poblado como un momento de tránsito del Bronce Inicial al Bronce Medio, o las sucesivas asignaciones al Bronce Medio avanzado apuntadas por Pellicer (1989: 166) o comienzos del Bronce Final I o Tardío (Martín de la Cruz et alii 1987: 204), sin que hayan faltado nuevamente opiniones sobre una "presencia Argárica" en el Guadalquivir (Gilman 1984/1992: 300), o se le haya asimilado al Bronce del Sudoeste (Lull et alii 1992: 270), pese a que aún no está claro que podamos ampliar al valle bajo del Guadalquivir este conjunto artefactual de las cistas de Huelva pese a los paralelismos de la cerámica de la sepultura del estrato XV de Setefilla.

Tal como puede apreciarse en las tablas con las propuestas cronológicas provisionales, la escasa representatividad de las dataciones actualmente disponibles siguen haciendo depender a Andalucía Occidental de las cronologías disponibles en el Sureste. Fases constatadas en Andalucía Oriental como el Calcolítico Final 2, Bronce Medio 1 y 2 o Bronce Final 1B-C están completamente ausentes, y en la mayoría de las ocasiones un periodo temporal sólo cuenta con una sola determinación, en ocasiones no muy fiable, de tal forma que esta propuesta resulta forzosamente provisional. 
En conclusión, lo que se ha tratado de exponer en este trabajo es que a través del análisis de los contextos de las dataciones por $\mathrm{C}^{14}$ publicadas hasta el momento, no sólo están comenzando a ayudar a articular la secuencia de la prehistoria reciente de Andalucía Occidental con cronologías absolutas, sino que resulta además un interesante reflejo de la investigación desarrollada en los últimos veinticinco años, balance sobre el que quizás convenga introducir elementos de reflexión a fin de definir las prioridades de investigación en los años venideros.

\section{Advertencias previas para consultar las tablas}

Las tablas se han organizado por etapas cronológicas (Neolítico, Calcolítico, Bronce Inicial-Medio y Bronce Final). Los yacimientos se agrupan por provincias (Málaga, Córdoba, Sevilla, Cádiz y Huelva) y dentro de éstas se sigue un orden alfabético. Las dataciones se ordenan dentro de cada yacimiento en función de su antigüedad. Las dataciones convencionales se muestran en 1s, o sea con un 63,3\% de posibilidades de que la fecha real se encuentre entre las datación obtenida y los máximos y mínimos de la desviación típica estadística, esto es, la cifra \pm que aparece detrás de cada datación, con 2 posibilidades entre 3 de acertar. Todas las dataciones calibradas están presentadas con $2 \mathrm{~s}$, que implica que existe un $95,4 \%$ de posibilidades de que la fecha real sea la que se sitúa entre los intervalos máximo y mínimo, o lo que es lo mismo, que contamos con 19 posibilidades entre 20 de situarnos entre la fecha correcta. La calibración se ha realizado con la versión 3.0.3. del programa Calib de Stuiver y Reimer (1993).

Las tablas con las propuestas cronológicas provisionales de la secuencia pretenden sintetizar información y seleccionar las dataciones más fiables con una muestra de yacimientos lo más amplia posible, lo que en ocasiones ha exigido poner algunas fechas no del todo óptimas. Se incorporan a título orientativo algunas dataciones procedentes de Jaén, cuya valoración ya ha sido desarrollada en otro trabajo (Mederos e.p.). Comentarios concretos de cada datación se encuentran en el texto precedente. Las dataciones convencionales se muestran con el valor medio obtenido por el laboratorio, y las dataciones calibradas, con los valores medios obtenidos por el programa dentro de la curva de calibración en los puntos de intersección, ya que ello facilita su análisis. Sin embargo no debe olvidarse que pueden remitirse a las tablas con todas las dataciones para ver los valores máximos y mínimos tanto de las dataciones convencionales, sumándoles y restándoles la cifra del \pm , como de las dataciones calibradas en sus intervalos máximo y mínimo.

\section{Agradecimientos}

Este trabajo se comenzó a elaborar durante la preparación de nuestra tesis doctoral (Mederos 1993), dirigida por D. Martín-Socas y $M^{a}$.D. Camalich, a fin de articular las secuencias de Andalucía Oriental y Occidental, y resulta un trabajo complementario de otro que hemos realizado para el Sureste de la Península Ibérica (Mederos e.p.). Los méritos de un trabajo de esta índole, si los hubiere, están compartidos con todos los investigadores que han dedicado parte de sus esfuerzos a secuenciar con nuevas dataciones la prehistoria de Andalucía Occidental, muchas veces incluso con sus propios recursos. Este trabajo está dedicado a las amigas y amigos sevillanos por sentirme siempre como en casa. 


\section{PROPUESTAS CRONOLÓGICAS PROVISIONALES}

\begin{tabular}{|l|c|c|c|c|}
\hline \multicolumn{1}{|c|}{ Yacimientos } & Neolítico Inicial & Neolítico Medio & Neolítico Final 1 & Neolítico Final 2 \\
\hline Nerja & $(6010,5940) 5290-4530$ & $4470-4250$ & 3840 & 3115 \\
\hline Dehesilla & $(5720)$ & $(4310)$ & & \\
\hline Toro & & $4450-4370$ & & $3500-3370$ \\
\hline Murciélagos Zuheros & & $4345-4075$ & & \\
\hline Chica de Santiago & & $(4210)$ & & 3570 \\
\hline Palomas & & & & $3550-3290$ \\
\hline Papauvas & & & & 3560 \\
\hline Propuesta provisional & $(6000) * 5300-4400$ a.C. & $4400-3900$ a.C. & $3900-3575$ a.C. & $3575-2900$ a.C. \\
\hline
\end{tabular}

* Las cifras entre paréntesis deben tomarse con reservas.

\begin{tabular}{|l|c|c|c|c|}
\hline \multicolumn{1}{|c|}{ Yacimientos } & Neolítico Inicial & Neolítico Medio & Neolítico Final 1 & Neolítico Final 2 \\
\hline Nerja & $\begin{array}{c}(6990 / 6770-6650) \\
6040-5430 / 5390\end{array}$ & $5330-5210 / 5090$ & $4680 / 4620$ & $3932 / 3810$ \\
\hline Dehesilla & $(6460)$ & $(5230)$ & & \\
\hline Toro & & $5320-5260$ & & $4330-3990$ \\
\hline Murciélagos Zuheros & & $5254-4923$ & & \\
\hline Chica de Santiago & & $(5070)$ & & 4350 \\
\hline Palomas & & & & $4350-4040 / 4000$ \\
\hline Papauvas & & & & 4350 \\
\hline Propuesta provisional & $(6700) 6100-5300$ A.C. & 5300-4900 A.C. & 4900-4350 A.C. & $4350-3700$ A.C. \\
\hline
\end{tabular}

\begin{tabular}{|l|c|c|c|c|}
\hline \multicolumn{1}{|c|}{ Yacimientos } & Calcolítico Inicial & Calcolítico Medio 1 & Calcolítico Medio 2 & Calcolítico Final \\
\hline Las Viñas & $(3000-2850)$ & & & \\
\hline Papauvas & 2890 & & & \\
\hline Negrón & & $2380-2300$ & & \\
\hline Cabeza-Valencina & & & 2100 & 1960 \\
\hline Amargillo II & & & 2080 & \\
\hline Albalate & & & $2130-2090$ & 1940 \\
\hline Propuesta Provisional & $2900-2500$ a.C. & $2500-2150$ a.C. & $2150-2025$ a.C. & $2025-1875$ a.C. \\
\hline
\end{tabular}


LA CRONOLOGÍA ABSOLUTA DE ANDALUCÍA OCCIDENTAL DURANTE LA PREHISTORIA RECIENTE (6100-850 A.C.) 73

\begin{tabular}{|l|c|c|c|c|}
\hline \multicolumn{1}{|c|}{ Yacimientos } & CalcolíticoInicial & CalcolíticoMedio 1 & Calcolítico Medio 2 & Calcolítico Final \\
\hline Las Viñas & $(3710-3630 / 3550)$ & & & \\
\hline Papauvas & 3640 & & & \\
\hline Negrón & & $2915-2884$ & & \\
\hline Cabeza-Valencina & & & $2570 / 2510$ & $2450 / 2410$ \\
\hline Amargillo II & & & $2560 / 2500$ & \\
\hline Albalate & & & $2590-2570 / 2500$ & $2400 / 2350$ \\
\hline Propuesta Provisional & $3700-3075$ A.C. & 3075-2625 A.C. & $2625-2475$ A.C. & $2475-2285$ A.C. \\
\hline
\end{tabular}

\begin{tabular}{|l|c|c|c|c|}
\hline \multicolumn{1}{|c|}{ Yacimientos } & $\begin{array}{c}\text { Calcolítico Final 3/ } \\
\text { Bronce Inicial 1 }\end{array}$ & Bronce Inicial 2 & Bronce Medio 1 & Bronce Medio 2 \\
\hline Cortijo Torre & 1880 & & & \\
\hline Albalate & 1880 & & & \\
\hline Acinipo & & $1700-1630$ & & \\
\hline Berrueco & & 1670 & & $(1570-1520)$ \\
\hline Setefilla & & & & $1470-1430$ \\
\hline Rincón Olvera & & & & $1470-1440$ \\
\hline Peñalosa & & & & $1580-1400$ a.C. \\
\hline Propuesta provisional & (2025) 1975-1775 a.C. & $1775-1640$ a.C. & $1640-1580$ a.C. & 158 \\
\hline
\end{tabular}

\begin{tabular}{|l|c|c|c|c|}
\hline \multicolumn{1}{|c|}{ Yacimientos } & $\begin{array}{c}\text { Calcolítico Final 3 } \\
\text { /Bronce Inicial 1 }\end{array}$ & Bronce Inicial 2 & Bronce Medio 1 & Bronce Medio 2 \\
\hline Cortijo Torre & 2280 & & & \\
\hline Albalate & 2280 & & & \\
\hline Acinipo & & $2020 / 1980-1910$ & & \\
\hline Berrueco & 1960 & & \\
\hline Setefilla & & & & $(1880 / 1790-1750)$ \\
\hline Rincón Olvera & & & & $1730 / 1690-1680$ \\
\hline Peñalosa & & & & $1730 / 1690-1680$ \\
\hline Propuesta provisional & (2475) 2285-2050 A.C. & $2050-1925$ A.C. & $1925-1830$ A.C. & $1830-1625$ A.C. \\
\hline
\end{tabular}




\begin{tabular}{|l|c|c|c|c|c|}
\hline \multicolumn{1}{|c|}{ Yacimientos } & $\begin{array}{c}\text { Bronce Medio 3- } \\
\text { Bronce Final 1A }\end{array}$ & $\begin{array}{c}\text { Bronce Final } \\
\text { 1B-C }\end{array}$ & $\begin{array}{c}\text { Bronce Final } \\
\text { II A-C }\end{array}$ & $\begin{array}{c}\text { Bronce } \\
\text { Final III A }\end{array}$ & $\begin{array}{c}\text { Fenicio-Bronce } \\
\text { Final IIIB }\end{array}$ \\
\hline Berrueco & 1360 & & & & \\
\hline Rincón Olvera & 1360 & & $1110-960$ & & \\
\hline Llanete Moros & & & 990 & & \\
\hline Loma del Puerto & & & & $880-850$ & \\
\hline Ría de Huelva & & & & $(880)$ & \\
\hline Mina Chinflón & & & & & $820-690$ \\
\hline Acinipo & & & & & 800 \\
\hline Mezquitilla & & & & & $(700)$ \\
\hline Chinflón & & & & & \\
\hline Propuesta provisional & $1400-1330$ a.C. & $1330-1150$ a.C. & $1150-950$ a.C. & $950-850$ a.C. & $850 \ldots$ a.C. \\
\hline
\end{tabular}

\begin{tabular}{|l|c|c|c|c|c|}
\hline \multicolumn{1}{|c|}{ Yacimientos } & $\begin{array}{c}\text { Bronce Medio 3 } \\
\text { Bronce Final 1A }\end{array}$ & $\begin{array}{c}\text { Bronce Final } \\
\text { 1B-C }\end{array}$ & $\begin{array}{c}\text { Bronce Final } \\
\text { II A-C }\end{array}$ & $\begin{array}{c}\text { Bronce } \\
\text { Final III A }\end{array}$ & $\begin{array}{c}\text { Fenicio-Bronce } \\
\text { Final IIIB }\end{array}$ \\
\hline Berrueco & $1600 / 1530$ & & & & \\
\hline Rincón Olvera & $1600 / 1530$ & & & & \\
\hline Llanete Moros & & & $1310-1045$ & & \\
\hline Loma del Puerto & & & 1120 & & \\
\hline Ría de Huelva & & & & $987-922$ & \\
\hline Mina Chinflón & & & & $(987-944)$ & \\
\hline Acinipo & & & & & $910-810$ \\
\hline Mezquitilla & & & & & $897-870$ \\
\hline Chinflón & $1625-1525$ & $1525-$ & $1325-1050$ & $1050-$ & $950 / 925 \ldots$ \\
\hline $\begin{array}{l}\text { Propuesta } \\
\text { provisional }\end{array}$ & A.C. & $\begin{array}{c}1325 / 1300 \\
\text { A.C. }\end{array}$ & A.C. & $950 / 925$ & A.C. \\
\hline
\end{tabular}


LA CRONOLOGÍA ABSOLUTA DE ANDALUCÍA OCCIDENTAL DURANTE LA PREHISTORIA RECIENTE (6100-850 A.C.) 75

\section{NEOLÍTICO}

\begin{tabular}{|c|c|c|c|c|c|c|c|c|}
\hline Yacimiento & Municipio-Provincia & B.P. & \pm & a.C. & $\begin{array}{l}\text { máx. } \\
\text { CAL }\end{array}$ & $\begin{array}{l}\text { CAL } \\
\text { B.C. }\end{array}$ & $\begin{array}{l}\min . \\
\text { CAL }\end{array}$ & $\begin{array}{c}\mathrm{n}^{\circ} \text { y tipo de } \\
\text { muestra }\end{array}$ \\
\hline Cueva de Nerja & Nerja, Málaga & 7960 & 200 & 6010 & 7430 & $\begin{array}{l}6990 \\
6960 \\
6860 \\
6850 \\
6770\end{array}$ & 6388 & $\mathrm{GaK}-8962 / \mathrm{C}$ \\
\hline Cueva de Nerja & Nerja, Málaga & 7890 & 170 & 5940 & 7262 & 6650 & 6382 & GaK-8974/C \\
\hline Cueva de Nerja & Nerja, Málaga & 7240 & 80 & 5290 & 6188 & 6040 & 5893 & $?$ \\
\hline Cueva de Nerja & Nerja, Málaga & 7160 & 150 & 5210 & 6293 & 5980 & 5691 & $\mathrm{GaK}-8963 / \mathrm{C}$ \\
\hline Cueva de Nerja & Nerja, Málaga & 7130 & 150 & 5180 & 6219 & 5970 & 5673 & $\mathrm{GaK}-8975 / \mathrm{C}$ \\
\hline Cueva de Nerja & Nerja, Málaga & 6200 & 100 & 4250 & 5321 & $\begin{array}{l}5210 \\
5170 \\
5140 \\
5110 \\
5090 \\
\end{array}$ & 4862 & UGRA-261/? \\
\hline Cueva de Nerja & Nerja, Málaga & 7160 & 180 & 5210 & 6372 & 5980 & 5633 & GaK-8973/S \\
\hline Cueva de Nerja & Nerja, Málaga & 6480 & 180 & 4530 & 5679 & $\begin{array}{l}5430 \\
5390\end{array}$ & 5050 & $\mathrm{GaK}-8959 / \mathrm{C}$ \\
\hline Cueva de Nerja & Nerja, Málaga & 6420 & 60 & 4470 & 5442 & 5330 & 5255 & $?$ \\
\hline Cueva de Nerja & Nerja, Málaga & 7170 & 150 & 5220 & 6352 & 5990 & 5697 & $\mathrm{GaK}-8971 / \mathrm{C}$ \\
\hline Cueva de Nerja & Nerja, Málaga & 5790 & 140 & 3840 & 4946 & $\begin{array}{l}4680 \\
4630 \\
4620\end{array}$ & 4348 & $\mathrm{GaK}-8969 / \mathrm{C}$ \\
\hline Cueva de Nerja & Nerja, Málaga & 5065 & 40 & 3115 & 3964 & $\begin{array}{l}3932 \\
3873 \\
3810 \\
\end{array}$ & 3773 & GrN-5526/S \\
\hline Cueva del Toro & Antequera, Málaga & 6400 & 280 & 4450 & 5772 & 5320 & 4719 & UGRA-194/C \\
\hline Cueva del Toro & Antequera, Málaga & 6320 & 70 & 4370 & $54 \overline{26}$ & 5260 & 5076 & GrN-15443/C \\
\hline Cueva del Toro & Antequera, Málaga & 5450 & 120 & 3500 & 4520 & 4330 & 3989 & $\mathrm{GaK}-8060 / \mathrm{C}$ \\
\hline Cueva del Toro & Antequera, Málaga & 5320 & 230 . & 3370 & 4675 & $\begin{array}{l}4220 \\
4200 \\
4150 \\
4110 \\
\end{array}$ & 3647 & $\begin{array}{c}\text { GaK-8059/ } \\
\text { CBNT }\end{array}$ \\
\hline Cueva del Toro & Antequera, Málaga & 5200 & 60 & 3250 & 4220 & 3990 & 3817 & GrN-15437/C \\
\hline $\begin{array}{l}\text { Cueva de las } \\
\text { Palomas }\end{array}$ & Teba, Málaga & 5840 & 210 & 3890 & 5226 & 4720 & 4258 & UGRA-204/C \\
\hline
\end{tabular}




\begin{tabular}{|c|c|c|c|c|c|c|c|c|}
\hline Yacimiento & Municipio-Provincia & B.P. & \pm & a.C. & $\begin{array}{l}\text { máx. } \\
\text { CAL }\end{array}$ & $\begin{array}{l}\text { CAL } \\
\text { B.C. }\end{array}$ & $\begin{array}{l}\min . \\
\text { CAL }\end{array}$ & $\begin{array}{c}n^{\circ} \text { y tipo de } \\
\text { muestra }\end{array}$ \\
\hline $\begin{array}{l}\text { Cueva de las } \\
\text { Palomas }\end{array}$ & Teba, Málaga & 5500 & 130 & 3550 & 4597 & 4350 & 4002 & UGRA-198/C \\
\hline $\begin{array}{l}\text { Cueva de las } \\
\text { Palomas }\end{array}$ & Teba, Málaga & 5470 & 130 & 3520 & 4546 & 4340 & 3989 & UGRA-177/C \\
\hline $\begin{array}{l}\text { Cueva de las } \\
\text { Palomas }\end{array}$ & Teba, Málaga & 5370 & 100 & 3420 & 4445 & 4230 & 3973 & UGRA-161/C \\
\hline $\begin{array}{l}\text { Cueva de las } \\
\text { Palomas }\end{array}$ & Teba, Málaga & 5240 & 110 & 3290 & 4334 & $\begin{array}{l}4040 \\
4020 \\
4000\end{array}$ & 3791 & UGRA-162/S \\
\hline $\begin{array}{l}\text { Cueva de los } \\
\text { Murciélagos }\end{array}$ & Zuheros, Córdoba & 6295 & 45 & 4345 & 5312 & 5254 & 5087 & GrN-6926/? \\
\hline $\begin{array}{l}\text { Cueva de los } \\
\text { Murciélagos }\end{array}$ & Zuheros, Córdoba & 6250 & 35 & 4300 & 5264 & 5223 & 5075 & GrN-6638/C \\
\hline $\begin{array}{l}\text { Cueva de los } \\
\text { Murciélagos }\end{array}$ & Zuheros, Córdoba & 5980 & 130 & 4030 & 5220 & $\begin{array}{l}4900 \\
4880 \\
4850\end{array}$ & 4539 & CSIC-57/S \\
\hline $\begin{array}{l}\text { Cueva de los } \\
\text { Murciélagos }\end{array}$ & Zuheros, Córdoba & 5860 & 130 & 4010 & 5051 & $\begin{array}{l}4760 \\
4740 \\
4730\end{array}$ & 4407 & CSIC-56/C \\
\hline $\begin{array}{l}\text { Cueva de los } \\
\text { Murciélagos }\end{array}$ & Zuheros, Córdoba & 6190 & 130 & 4240 & 5421 & $\begin{array}{l}5200 \\
5180 \\
5140 \\
5120 \\
5080\end{array}$ & 4799 & CSIC-53/S \\
\hline $\begin{array}{l}\text { Cueva de los } \\
\text { Murciélagos }\end{array}$ & Zuheros, Córdoba & 6190 & 130 & 4240 & 5421 & $\begin{array}{l}5200 \\
5180 \\
5140 \\
5120 \\
5080\end{array}$ & 4799 & CSIC-54/S \\
\hline $\begin{array}{l}\text { Cueva de los } \\
\text { Murciélagos }\end{array}$ & Zuheros, Córdoba & 6150 & 45 & 4200 & 5221 & 5064 & 4941 & GrN-6169/S \\
\hline $\begin{array}{l}\text { Cueva de los } \\
\text { Murciélagos }\end{array}$ & Zuheros, Córdoba & 6170 & 130 & 4220 & 5373 & $\begin{array}{l}5190 \\
5130 \\
5070\end{array}$ & 4787 & CSIC-55/S \\
\hline $\begin{array}{l}\text { Cueva de los } \\
\text { Murciélagos }\end{array}$ & Zuheros, Córdoba & 6100 & 130 & 4150 & 5279 & 4990 & 4719 & CSIC-58/C \\
\hline $\begin{array}{l}\text { Cueva de los } \\
\text { Murciélagos }\end{array}$ & Zuheros, Córdoba & 6025 & 45 & 4075 & 5051 & 4923 & 4800 & GrN-6639/S \\
\hline
\end{tabular}


LA CRONOLOGÍA ABSOLUTA DE ANDALUCÍA OCCIDENTAL DURANTE LA PREHISTORIA RECIENTE (6100-850 A.C.) 77

\begin{tabular}{|l|l|c|c|c|c|c|c|c|}
\hline \multicolumn{1}{|c|}{ Yacimiento } & Municipio-Provincia & B.P. & \pm & a.C. & $\begin{array}{c}\text { máx. } \\
\text { CAL }\end{array}$ & $\begin{array}{l}\text { CAL } \\
\text { B.C. }\end{array}$ & $\begin{array}{c}\text { min. } \\
\text { CAL }\end{array}$ & $\begin{array}{c}\text { n y tipo de } \\
\text { muestra }\end{array}$ \\
\hline $\begin{array}{l}\text { Cueva de los } \\
\text { Murciélagos }\end{array}$ & Zuheros, Córdoba & 5930 & 130 & 3980 & 5202 & 4800 & 4495 & CSIC-59/C \\
\hline $\begin{array}{l}\text { Cueva Chica } \\
\text { de Santiago }\end{array}$ & $\begin{array}{l}\text { Cazalla de la Sierra, } \\
\text { Sevilla }\end{array}$ & 7890 & 180 & 5940 & 7290 & 6650 & 6375 & GaK-8952/C \\
\hline $\begin{array}{l}\text { Cueva Chica } \\
\text { de Santiago }\end{array}$ & $\begin{array}{l}\text { Cazalla de la Sierra, } \\
\text { Sevilla }\end{array}$ & 7240 & 230 & 5290 & 6467 & 6040 & 5620 & GaK-8947/C \\
\hline $\begin{array}{l}\text { Cueva Chica } \\
\text { de Santiago }\end{array}$ & $\begin{array}{l}\text { Cazalla de la Sierra, } \\
\text { Sevilla }\end{array}$ & 6380 & 150 & 4430 & 5577 & 5290 & 4950 & GaK-8949/C \\
\hline $\begin{array}{l}\text { Cueva Chica } \\
\text { de Santiago }\end{array}$ & $\begin{array}{l}\text { Cazalla de la Sierra, } \\
\text { Sevilla }\end{array}$ & 5520 & 120 & 3570 & 4597 & 4350 & 4045 & GaK-8948/C \\
\hline $\begin{array}{l}\text { Cueva Chica } \\
\text { de Santiago }\end{array}$ & $\begin{array}{l}\text { Cazalla de la Sierra, } \\
\text { Sevilla }\end{array}$ & 6160 & 120 & 4210 & 5321 & 5070 & 4791 & UGRA-254/C \\
\hline $\begin{array}{l}\text { Cueva Chica } \\
\text { de Santiago }\end{array}$ & $\begin{array}{l}\text { Cazalla de la Sierra, } \\
\text { Sevilla }\end{array}$ & 7040 & 180 & 5090 & 6187 & $\begin{array}{l}5910 \\
5870\end{array}$ & 5529 & GaK-8951/C \\
\hline $\begin{array}{l}\text { Cueva Chica } \\
\text { de Santiagc }\end{array}$ & $\begin{array}{l}\text { Cazalla de la Sierra, } \\
\text { Sevilla }\end{array}$ & 5100 & 120 & 3150 & 4224 & $\begin{array}{l}3950 \\
3830\end{array}$ & 3646 & GaK-8950/C \\
\hline $\begin{array}{l}\text { Cueva de la } \\
\text { Dehesilla }\end{array}$ & $\begin{array}{l}\text { Jerez de la Frontera, } \\
\text { Cádiz }\end{array}$ & 6260 & 100 & 4310 & 5426 & 5230 & 4941 & UGRA-259/C \\
\hline $\begin{array}{l}\text { Cueva de la } \\
\text { Dehesilla }\end{array}$ & $\begin{array}{l}\text { Jerez de la Frontera, } \\
\text { Cádiz }\end{array}$ & 7670 & 400 & 5720 & 7499 & 6460 & 5697 & GaK-8953/C \\
\hline $\begin{array}{l}\text { Cueva de la } \\
\text { Dehesilla }\end{array}$ & $\begin{array}{l}\text { Jerez de la Frontera, } \\
\text { Cádiz }\end{array}$ & 7120 & 200 & 5170 & 6372 & 5960 & 5591 & GaK-8954/C \\
\hline $\begin{array}{l}\text { Cueva de la } \\
\text { Dehesilla }\end{array}$ & $\begin{array}{l}\text { Jerez de la Frontera, } \\
\text { Cádiz }\end{array}$ & 7040 & 170 & 5090 & 6182 & $\begin{array}{l}5910 \\
5870\end{array}$ & 5583 & GaK-8955/C \\
\hline $\begin{array}{l}\text { Cueva de la } \\
\text { Dehesilla }\end{array}$ & $\begin{array}{l}\text { Jerez de la Frontera, } \\
\text { Cádiz }\end{array}$ & 5920 & 160 & 3970 & 5226 & 4790 & 4369 & GaK-8956/C \\
\hline Papauvas & Aljaraque, Huelva & 5510 & 300 & 3560 & 5041 & 4350 & 3695 & UGRA-329/H \\
\hline
\end{tabular}

$\mathrm{C} /=$ Corte $. \mathrm{N}=$ Nivel. Tipos de muestras: $\mathrm{C}=$ Carbón; $\mathrm{M}=$ Madera; $\mathrm{S}=$ Semilla; $\mathrm{H}=$ Hueso; $\mathrm{CO}=$ Concha; $\mathrm{CBNT}=$ Carbonatos. 


\section{CALCOLÍTICO}

\begin{tabular}{|c|c|c|c|c|c|c|c|c|}
\hline Yacimiento & Municipio-Provincia & B.P. & \pm & a.C. & $\begin{array}{l}\text { máx. } \\
\text { CAL }\end{array}$ & $\begin{array}{l}\text { CAL } \\
\text { B.C. }\end{array}$ & $\begin{array}{l}\min . \\
\text { CAL }\end{array}$ & $\begin{array}{c}\mathrm{n}^{\mathrm{o}} \text { y tipo de } \\
\text { muestra }\end{array}$ \\
\hline Cueva de Nerja & Nerja, Málaga & 4810 & 210 & 2860 & 4032 & 3630 & 2928 & $\mathrm{GaK}-8960 / \mathrm{C}$ \\
\hline $\begin{array}{l}\text { Cerro del Castillo. } \\
\text { Nivel } 42\end{array}$ & Monturque, Córdoba & 3390 & 110 & 1440 & 1944 & 1680 & 1423 & UGRA-323/C \\
\hline $\begin{array}{l}\text { Cerro del Castillo. } \\
\text { Nivel } 36\end{array}$ & Monturque, Córdoba & 4120 & 160 & 2170 & 3085 & $\begin{array}{l}2850 \\
2830 \\
2650 \\
2640 \\
2620\end{array}$ & 2200 & UGRA-303/C \\
\hline Amarguillo II & Sevilla & 4030 & 65 & 2080 & 2862 & $\begin{array}{l}2560 \\
2520 \\
2500\end{array}$ & 2361 & OxA-3971/C \\
\hline $\begin{array}{l}\text { Cerro de la } \\
\text { Cabeza. } \\
\text { Valencina }\end{array}$ & $\begin{array}{l}\text { Valencina de la } \\
\text { Concepción, Sevilla }\end{array}$ & 4050 & 105 & 2100 & 2885 & $\begin{array}{l}2570 \\
2510\end{array}$ & 2284 & $\mathrm{I}-10.187 / ?$ \\
\hline $\begin{array}{l}\text { Cerro de la } \\
\text { Cabeza. } \\
\text { Valencina }\end{array}$ & $\begin{array}{l}\text { Valencina de la } \\
\text { Concepción, Sevilla }\end{array}$ & 3910 & 110 & 1960 & 2853 & $\begin{array}{l}2450 \\
2420 \\
2410\end{array}$ & 2038 & Gif-4.028/C \\
\hline $\begin{array}{l}\text { Valencina de la } \\
\text { Concepción }\end{array}$ & $\begin{array}{l}\text { Valencina de la } \\
\text { Concepción, Sevilla }\end{array}$ & 3380 & 150 & 1430 & 2035 & 1680 & 1320 & UGRA-72/H \\
\hline El Negrón & Gilena, Sevilla & 4330 & 35 & 2380 & 3030 & 2915 & 2885 & $? / \mathrm{C}$ \\
\hline El Negrón & Gilena, Sevilla & 4300 & 35 & 2350 & 3011 & 2906 & 2878 & $? / \mathrm{C}$ \\
\hline El Negrón & Gilena, Sevilla & 4250 & 35 & 2300 & 2913 & 2884 & 2702 & $? / \mathrm{C}$ \\
\hline \begin{tabular}{|l|} 
Universidad \\
Laboral de Sevilla
\end{tabular} & $\begin{array}{l}\text { Alcalá de Guadaira, } \\
\text { Sevilla }\end{array}$ & 3190 & 120 & 1240 & 1737 & 1440 & 1129 & $\mathrm{I}-10.764 / \mathrm{C}$ \\
\hline Las Viñas. Silo 16 & $\begin{array}{l}\text { Puerto de Santa } \\
\text { María, Cádiz }\end{array}$ & 4950 & 60 & 3000 & 3934 & 3710 & 3638 & $\begin{array}{l}\text { UGRA- } \\
370 / \mathrm{CO}\end{array}$ \\
\hline Las Viñas. Silo 50 & $\begin{array}{l}\text { Puerto de Santa } \\
\text { María, Cádiz } \\
\end{array}$ & 4800 & 90 & 2850 & 3773 & $\begin{array}{l}3630 \\
3550 \\
\end{array}$ & 3363 & $\begin{array}{l}\text { UGRA- } \\
369 / \mathrm{CO} \\
\end{array}$ \\
\hline Papauvas & Aljaraque, Huelva & 4840 & 120 & 2890 & 3938 & 3640 & 3356 & CSIC-485/C \\
\hline Papauvas & Aljaraque, Huelva & 4110 & 50 & 2160 & 3304 & 3033 & 2910 & CSIC-654/CO \\
\hline
\end{tabular}

$\mathrm{C} /=$ Corte. $\mathrm{N}=$ Nivel. Tipos de muestras: $\mathrm{C}=$ Carbón; $\mathrm{M}=$ Madera; $\mathrm{S}=\mathrm{Semilla} ; \mathrm{H}=$ Hueso; $\mathrm{CO}=\mathrm{Concha}$; CBNT $=$ Carbonatos. 


\section{BRONCE INICIAL Y MEDIO}

\begin{tabular}{|l|l|c|c|c|c|c|c|c|}
\hline \multicolumn{1}{|c|}{ Yacimiento } & Municipio-Provincia & B.P. & \pm & a.C. & $\begin{array}{l}\text { máx. } \\
\text { CAL }\end{array}$ & $\begin{array}{l}\text { CAL } \\
\text { B.C. }\end{array}$ & $\begin{array}{c}\text { min. } \\
\text { CAL }\end{array}$ & $\begin{array}{c}\text { n- y tipo de } \\
\text { muestra }\end{array}$ \\
\hline $\begin{array}{l}\text { Cortijo del } \\
\text { Tardón. Sep. 1 }\end{array}$ & Antequera, Málaga & 3530 & 70 & 1580 & 2032 & $\begin{array}{c}1880 \\
1830 \\
1790\end{array}$ & 1679 & $\begin{array}{c}\text { UGRA- } \\
\text { 260/H }\end{array}$ \\
\hline $\begin{array}{l}\text { Ronda la Vieja- } \\
\text { Acinipo }\end{array}$ & Ronda, Málaga & 3580 & 100 & 1630 & 2193 & 1910 & 1676 & I-?/C \\
\hline $\begin{array}{l}\text { Ronda la Vieja- } \\
\text { Acinipo }\end{array}$ & Ronda, Málaga & 3650 & 80 & 1700 & 2273 & 2020 & 1771 & I-?/C \\
\hline $\begin{array}{l}\text { Ronda la Vieja- } \\
\text { Acinipo }\end{array}$ & Ronda, Málaga & 2980 & 90 & 1030 & 1420 & 1250 & 921 & I-?/C \\
\hline $\begin{array}{l}\text { Monte Berrueco. } \\
\text { N. 2 }\end{array}$ & $\begin{array}{l}\text { Medina Sidonia, } \\
\text { Cádiz }\end{array}$ & 3620 & 80 & 1670 & 2193 & 1960 & 1745 & I-?/C \\
\hline Pisotilla & Huelva & 3860 & 70 & 1910 & 2131 & 2320 & 1955 AD & BM-1603/C \\
\hline
\end{tabular}

$\mathrm{C} /=$ Corte. $\mathrm{N}=$ Nivel. Tipos de muestras: $\mathrm{C}=$ Carbón y $\mathrm{H}=$ Hueso

\section{BRONCE FINAL}

\begin{tabular}{|c|c|c|c|c|c|c|c|c|}
\hline Yacimiento & $\begin{array}{l}\text { Municipio- } \\
\text { Provincia }\end{array}$ & B.P. & \pm & a.C. & $\begin{array}{l}\text { máx. } \\
\text { CAL }\end{array}$ & $\begin{array}{l}\text { CAL } \\
\text { B.C. }\end{array}$ & $\begin{array}{l}\min . \\
\mathrm{CAL}\end{array}$ & $\begin{array}{c}\mathrm{n}^{\circ} \text { y tipo de } \\
\text { muestra }\end{array}$ \\
\hline $\begin{array}{l}\text { Cerro del Castillo. } \\
\text { Nivel } 22\end{array}$ & $\begin{array}{l}\text { Monturque, } \\
\text { Córdoba }\end{array}$ & 3040 & 90 & 1090 & 1506 & $\begin{array}{l}1290 \\
1280 \\
1270\end{array}$ & 1004 & $\begin{array}{l}\text { UGRA- } \\
308 / C\end{array}$ \\
\hline $\begin{array}{l}\text { Cerro del Castillo. } \\
\text { Nivel } 13\end{array}$ & $\begin{array}{l}\text { Monturque, } \\
\text { Córdoba }\end{array}$ & 3190 & 90 & 1240 & 1674 & 1440 & 1226 & $\begin{array}{l}\text { UGRA- } \\
311 / \mathrm{C}\end{array}$ \\
\hline $\begin{array}{l}\text { Llanete de los } \\
\text { Moros. C/2. Nivel } \\
\text { 8-fosa }\end{array}$ & Montoro, Córdoba & 3080 & 90 & 1130 & 1518 & $\begin{array}{l}1380 \\
1340 \\
1320\end{array}$ & 1043 & $\begin{array}{l}\text { UGRA- } \\
183 / C\end{array}$ \\
\hline $\begin{array}{l}\text { Llanete de los } \\
\text { Moros. C/3 }\end{array}$ & Montoro, Córdoba & 3060 & 60 & 1110 & 1430 & 1310 & 1123 & CSIC-795/? \\
\hline $\begin{array}{l}\text { Llanete de los } \\
\text { Moros. C/3 }\end{array}$ & Montoro, Córdoba & 3020 & 60 & 1070 & 1410 & 1260 & 1043 & CSIC-794/? \\
\hline $\begin{array}{l}\text { Llanete de los } \\
\text { Moros. C/2. Nivel } \\
\text { 8-fosa }\end{array}$ & Montoro, Córdoba & 3000 & 100 & 1050 & 1443 & $\begin{array}{l}1260 \\
1240 \\
1220\end{array}$ & 921 & $\begin{array}{l}\text { UGRA- } \\
160 / \mathrm{S}\end{array}$ \\
\hline
\end{tabular}




\begin{tabular}{|c|c|c|c|c|c|c|c|c|}
\hline Yacimiento & $\begin{array}{l}\text { Municipio- } \\
\text { Provincia }\end{array}$ & B.P. & \pm & a.C. & $\begin{array}{l}\text { máx. } \\
\text { CAL }\end{array}$ & $\begin{array}{l}\text { CAL } \\
\text { B.C. }\end{array}$ & $\begin{array}{l}\min . \\
\text { CAL }\end{array}$ & $\begin{array}{c}\text { no y tipo de } \\
\text { muestra }\end{array}$ \\
\hline $\begin{array}{l}\text { Llanete de los } \\
\text { Moros. C/1. N. IIIb }\end{array}$ & Montoro, Córdoba & 2980 & 130 & 1030 & 1513 & $\begin{array}{l}1250 \\
1200\end{array}$ & 837 & $\begin{array}{l}\text { UGRA- } \\
159 / \mathrm{C}\end{array}$ \\
\hline $\begin{array}{l}\text { Llanete de los } \\
\text { Moros. C/1. N. IIIa }\end{array}$ & Montoro, Córdoba & 2930 & 110 & 980 & 1415 & 1120 & 831 & $\begin{array}{l}\text { UGRA- } \\
190 / C\end{array}$ \\
\hline $\begin{array}{l}\text { Llanete de los } \\
\text { Moros. C/2. N. } 6\end{array}$ & Montoro, Córdoba & 2910 & 120 & 960 & 1415 & $\begin{array}{l}1110 \\
1100 \\
1060\end{array}$ & 813 & $\begin{array}{l}\text { UGRA- } \\
187 / \mathrm{C}\end{array}$ \\
\hline $\begin{array}{l}\text { Llanete de los } \\
\text { Moros. C/1-2. N. } 1\end{array}$ & Montoro, Córdoba & 2900 & 50 & 950 & 1257 & 1045 & 920 & CSIC-624/? \\
\hline $\begin{array}{l}\text { Llanete de los } \\
\text { Moros }\end{array}$ & Montoro, Córdoba & 2890 & 140 & 940 & 1424 & 1030 & 799 & $\begin{array}{l}\text { UGRA- } \\
175 / C\end{array}$ \\
\hline $\begin{array}{l}\text { Llanete de los } \\
\text { Moros. C/2. N. } 8\end{array}$ & Montoro, Córdoba & 2710 & 250 & 760 & 1494 & 830 & 205 & $\begin{array}{l}\text { UGRA- } \\
186 / \mathrm{S}\end{array}$ \\
\hline $\begin{array}{l}\text { Mesa de Setefilla. } \\
\text { N. } 14\end{array}$ & $\begin{array}{l}\text { Lora del Río, } \\
\text { Sevilla }\end{array}$ & 3520 & 95 & 1570 & 2129 & $\begin{array}{l}1880 \\
1840 \\
1820 \\
1800 \\
1790\end{array}$ & 1612 & $\mathrm{I}-11.070 / \mathrm{M}$ \\
\hline $\begin{array}{l}\text { Mesa de Setefilla. } \\
\text { N. } 13\end{array}$ & $\begin{array}{l}\text { Lora del Río, } \\
\text { Sevilla }\end{array}$ & 3470 & 95 & 1520 & 2026 & 1750 & 1522 & $\mathrm{I}-11.069 / \mathrm{M}$ \\
\hline $\begin{array}{l}\text { Monte Berrueco. } \\
\text { N. } 3\end{array}$ & $\begin{array}{l}\text { Medina Sidonia, } \\
\text { Cádiz }\end{array}$ & 3310 & 80 & 1360 & 1748 & $\begin{array}{l}1600 \\
1570 \\
1530\end{array}$ & 1413 & $\mathrm{I}-? / \mathrm{C}$ \\
\hline $\begin{array}{l}\text { Loma del Puerto. } \\
\text { Sep. } 6\end{array}$ & $\begin{array}{l}\text { Chiclana de la } \\
\text { Frontera, Cádiz }\end{array}$ & 2940 & 90 & 990 & 1401 & 1120 & 901 & $\begin{array}{l}\text { UBAR- } \\
346 / \mathrm{H}\end{array}$ \\
\hline $\begin{array}{l}\text { Chinflón. Mina } 3 . \\
\text { Nivel } 9\end{array}$ & $\begin{array}{l}\text { Zalamea la Real, } \\
\text { Huelva }\end{array}$ & 2830 & 50 & 880 & 1121 & $\begin{array}{l}987 \\
956 \\
944\end{array}$ & 841 & BM-1599/M \\
\hline Chinflón. Nivel 4 & $\begin{array}{l}\text { Zalamea la Real, } \\
\text { Huelva }\end{array}$ & 2520 & 210 & 570 & 1125 & 770 & 101 & BM-1600/C \\
\hline Chinflón. Nivel 3 & $\begin{array}{l}\text { Zalamea la Real, } \\
\text { Huelva }\end{array}$ & 3320 & 130 & 1370 & 1913 & $\begin{array}{l}1610 \\
1560 \\
1540\end{array}$ & 1312 & $\mathrm{BM}-1529 / \mathrm{C}$ \\
\hline Chinflón. Nivel 2 & $\begin{array}{l}\text { Zalamea la Real, } \\
\text { Huelva }\end{array}$ & 2650 & 60 & 700 & 907 & 810 & 767 & BM-1528/C \\
\hline Chinflón & $\begin{array}{l}\text { Zalamea la Real, } \\
\text { Huelva }\end{array}$ & 2520 & 210 & 570 & 1125 & 770 & 101 & BM-1601/C \\
\hline
\end{tabular}


LA CRONOLOGÍA ABSOLUTA DE ANDALUCÍA OCCIDENTAL DURANTE LA PREHISTORIA RECIENTE (6100-850 A.C.) 81

\begin{tabular}{|c|c|c|c|c|c|c|c|c|}
\hline Yacimiento & $\begin{array}{l}\text { Municipio- } \\
\text { Provincia }\end{array}$ & B.P. & \pm & a.C. & $\begin{array}{l}\text { máx. } \\
\text { CAL }\end{array}$ & $\begin{array}{l}\text { CAL } \\
\text { B.C. }\end{array}$ & $\begin{array}{l}\min . \\
\text { CAL }\end{array}$ & $\begin{array}{l}\mathrm{n}^{\mathrm{o}} \text { y tipo de } \\
\text { muestra }\end{array}$ \\
\hline Chinflón. Mina & $\begin{array}{l}\text { Zalamea la Real, } \\
\text { Huelva }\end{array}$ & 2350 & 100 & 400 & 779 & 400 & 180 & $\begin{array}{l}\text { BM-2064R } \\
\text { ¿celulosa? }\end{array}$ \\
\hline Ría de Huelva & Huelva & 2830 & 70 & 880 & 1198 & $\begin{array}{l}987 \\
956 \\
944 \\
\end{array}$ & 821 & CSIC-202/M \\
\hline Ría de Huelva & Huelva & 2820 & 70 & 860 & 1160 & $\begin{array}{l}976 \\
965 \\
935\end{array}$ & 821 & CSIC-203/M \\
\hline Ría de Huelva & Huelva & 2820 & 70 & 870 & 1160 & $\begin{array}{l}976 \\
965 \\
935\end{array}$ & 817 & CSIC-206/M \\
\hline Ría de Huelva & Huelva & 2820 & 70 & 870 & 1160 & $\begin{array}{l}976 \\
965 \\
935 \\
\end{array}$ & 817 & CSIC-207/M \\
\hline Ría de Huelva & Huelva & 2810 & 70 & 860 & 1154 & 927 & 813 & CSIC-205/M \\
\hline Ría de Huelva & Huelva & 2800 & 70 & 850 & 1126 & 922 & 809 & CSIC-204/M \\
\hline
\end{tabular}

$\mathrm{C} /=$ Corte. $\mathrm{N}=$ Nivel. Tipos de muestras: $\mathrm{C}=$ Carbón; $\mathrm{H}=$ Hueso; $\mathrm{M}=$ Madera y $\mathrm{S}=$ Semilla..

PRIMEROS FENICIOS E INICIOS DE LA ACULTURACIÓN

\begin{tabular}{|l|l|c|c|c|c|c|c|c|}
\hline \multicolumn{1}{|c|}{ Yacimiento } & Municipio-Provincia & B.P. & \pm & a.C. & $\begin{array}{l}\text { máx. } \\
\text { CAL }\end{array}$ & $\begin{array}{l}\text { CAL } \\
\text { B.C. }\end{array}$ & $\begin{array}{c}\text { min. } \\
\text { CAL }\end{array}$ & $\begin{array}{c}\text { no y tipo } \\
\text { de muestra }\end{array}$ \\
\hline Ronda la Vieja-Acinipo & Ronda, Málaga & 2770 & 90 & 820 & 1153 & 910 & 794 & I-?/C \\
\hline Ronda la Vieja-Acinipo & Ronda, Málaga & 2650 & 90 & 700 & 988 & 810 & 532 & I-?/C \\
\hline Ronda la Vieja-Acinipo & Ronda, Málaga & 2640 & 180 & 690 & 1256 & 810 & 376 & I-?/C \\
\hline $\begin{array}{l}\text { Morro de Mezquitilla. } \\
\text { Fase A-B.1 }\end{array}$ & $\begin{array}{l}\text { Vélez-Málaga, } \\
\text { Málaga }\end{array}$ & 2750 & 50 & 800 & 999 & 897 & 807 & B-4178/C \\
\hline Morro de Mezquitilla & Vélez-Málaga, Málaga & 2640 & 30 & 690 & 828 & 805 & 792 & $?$ \\
\hline $\begin{array}{l}\text { Morro de Mezquitilla. } \\
\text { Fase B.1 }\end{array}$ & $\begin{array}{l}\text { Vélez-Málaga, } \\
\text { Málaga }\end{array}$ & 2570 & 50 & 620 & 814 & 790 & 532 & B-4180/? \\
\hline $\begin{array}{l}\text { Morro de Mezquitilla. } \\
\text { Fase B.2 }\end{array}$ & $\begin{array}{l}\text { Vélez-Málaga, } \\
\text { Málaga }\end{array}$ & 2560 & 50 & 610 & 810 & 785 & 524 & B-4175/? \\
\hline
\end{tabular}

Muestras: C= Carbón. 
ALFREDO MEDEROS MARTÍN

\section{BIBLIOGRAFÍA}

ACOSTA, P. y CRUZ-AUÑóN, R. (1981): "Los enterramientos de las fases iniciales de la "Cultura de Almería"”, Habis 12: 275-360.

ACOSTA, P. y PELLICER, M. (1990): La Cueva de la Dehesilla (Jerez de la Frontera): las Primeras Civilizaciones Productoras en Andalucía Occidental, Centro de Estudios Históricos Jerezanos. Jerez de la Frontera.

AGUADO, T. y BALDOMERO, A. (1979): "Estudio de los materiales de superficie de la "Cueva de las Palomas" (Teba, Málaga)", Mainake 1: 29-59.

AGUAYO, P.; CARRILERO, M.; FLORES, C. y TORRE, M.del P. de la (1986): "El yacimiento pre y protohistórico de Acinipo (Ronda, Málaga): un ejemplo de Cabañas del Bronce Final y su evolución”, Coloquio sobre el Microespacio 3: Del Bronce Final a Época Ibérica (Teruel, 1986), Arqueología Espacial 9: 33-58.

AGUAYO, P.; CARRILERO, M.; MARTÍNEZ, G.; AFONSO, J.A.; GARRIDO, O. y PADIAL, B. (1991): "Excavaciones arqueológicas en el yacimiento de Ronda la Vieja (Acinipo). Campaña de 1988", Anuario Arqueológico de Andalucía 1988. II. Actividades Sistemáticas, Consejería de Cultura y Medio Ambiente de la Junta de Andalucía. Sevilla: 309-314.

AGUAYO, P.; CARRILERO, M.; TORRE, M. del P. de la y FLORES, C. (1987): "El yacimiento pre y protohistórico de Acinipo (Ronda, Málaga). Campaña de 1985", Anuario Arqueológico de Andalucía 1985. II. Actividades Sistemáticas, Consejería de Cultura de la Junta de Andalucía. Sevilla: 294-304.

ALMAGRO BASCH, M. (1962): El ajuar del 'Dolmen de la Pastora' de Valencina del Alcor (Sevilla). Sus paralelos y su cronología, Trabajos de Prehistoria 5. Madrid.

ALMAGRO-GORBEA, M. (1977): El Bronce Final y el Periodo Orientalizante en Extremadura, Bibliotheca Praehistórica Hispana XIV, C.S.I.C. Madrid.

AMBERS, J.; MATTHEWS, K. y BOWMAN, S. (1991): "British Museum natural radiocarbon measurements XXII", Radiocarbon 33: 51-58.

AUBET, M.E. (1975): La necrópolis de Setefilla en Lora del Río, Sevilla (túmulo A), C.S.I.C. Barcelona. (1978): La necrópolis de Setefilla en Lora del Río, Sevilla (túmulo B), C.S.I.C. Barcelona. (1981): "Sepulturas de la Edad del Bronce en la:Mesa de Setefilla (Sevilla)", Madrider Mitteilungen 22: 127-149.

- (1989): "La mesa de Setefilla: la secuencia estratigráfica del corte 1". En M".E. Aubet (ed.) "Tartessos. Arqueología Protohistórica del Bajo Guadalquivir", Ausa. Sabadell-Barcelona: 297-338.

- (1994): Tiro y las colonias fenicias de Occidente, Crítica, Barcelona. $2^{\mathrm{a}}$ Edición.

AUBET, M.E. y SERNA, M.R. (1981): "Una sepultura de la Edad del Bronce en Setefilla (Sevilla)", Trabajos de Prehistoria 38: 225-255.

AUBET, M.E.; SERNA, M.R.; ESCACENA, J.L. y RUIZ DELGADO, M.M. (1983): La Mesa de Setefilla, Lora del Río (Sevilla). Campaña de 1979, Excavaciones Arqueológicas en España 122. Madrid.

BERNABÉU, J. (1989): La tradición cultural de las cerámicas impresas en la zona oriental de la Península Ibérica, Trabajos Varios del Servicio de Investigación Prehistórica 86, Valencia.

BOWMAN, S.G.E.; AMBERS, J.C. y LEESE, M.N. (1990): "Re-evaluation of British Museum radiocarbon dates issued between 1980 and 1984", Radiocarbon 32: 59-79.

BURLEIGH, R.; AMBERS, J. y MATTHEWS, K. (1984): "British Museum natural radiocarbon measurements XVII", Radiocarbon 26: 59-74.

BURLEIGH, R.; MATTHEWS, K. y AMBERS, J. (1982): "British Museum natural radiocarbon measurements XIV", Radiocarbon 24: 229-261 
CABRERO, R. (1987): "Informe preliminar sobre las excavaciones arqueológicas realizadas en el yacimiento de Amarguillo II (Los Molares, Sevilla)", Anuario Arqueológico de Andalucía 1986. II. Actividades Sistemáticas, Consejería de Cultura de la Junta de Andalucía. Sevilla: 180-185.

- (1990): "El poblado de la Edad del Cobre denominado Amarguillo II (Los Molares, Sevilla). Informe preliminar tras la excavación sistemática de 1987", Anuario Arqueológico de Andalucía 1987. II. Actividades Sistemáticas, Consejería de Cultura de la Junta de Andalucía. Sevilla: 276-277.

CARRIAZO, J. de M. (1974): Protohistoria de Sevilla. En el vértice de Tartessos, Ediciones Guadalquivir. Sevilla.

CHAPMAN, R.W. (1990): Emerging Complexity. The Later Prehistory of South-East Spain, Iberia and the West Mediterranean, Cambridge University Press. Cambridge.

- (1991): La formación de las sociedades complejas. El sureste de la península ibérica en el marco del Mediterráneo occidental, Crítica. Barcelona.

CRUZ-AUÑÓN, R.; MORENO, E. y CÁCERES, P. (1992): "Estudio de materiales en el yacimiento del Negrón (Gilena, Sevilla)", Anuario Arqueológico de Andalucía 1990. II. Actividades Sistemáticas, Consejería de Cultura de la Junta de Andalucía, Sevilla: 277-280.

_ (1993): "Proyecto. Estudio del hábitat Calcolítico en el pie de sierra del Bajo Valle del Guadalquivir", Investigaciones Arqueológicas en Andalucía 1985-1992. Proyectos, Consejería de Cultura y Medio Ambiente de la Junta de Andalucía. Huelva: 373-382.

CRUZ-AUÑÓN, R. y RIVERO, E. (1987): "Prospección con sondeos en el yacimiento prehistórico de El Negrón (Gilena, Sevilla)", Anuario Arqueológico de Andalucía 1986. II. Actividades Sistemáticas, Consejería de Cultura de la Junta de Andalucía, Sevilla: 175-179.

- (1990): "Yacimiento del Negrón (Gilena, Sevilla). Campaña 1987", Anuario Arqueológico de Andalucía 1987. II. Actividades Sistemáticas, Consejería de Cultura de la Junta de Andalucía. Sevilla: 278-280.

DELIBES, G. y FERNÁNDEZ-MIRANDA, M. (1986-87) “Aproximación a la cronología del grupo Cogotas I", Zephyrus 39-40: 17-30

DELIBES, G. y ROMERO, F. (1992): "El último milenio a.C. en la Cuenca del Duero. Reflexiones sobre la secuencia cultural", Complutum 2-3: 233-258.

ESCACENA, J.L. y BERRIATÚA, N. (1985): "El Berrueco de Medina Sidonia (Cádiz). Testimonios de una probable expansión argárica hacia el oeste", Cuadernos de Prehistoria de la Universidad de Granada 10: $225-242$.

ESCACENA, J.L. y FRUTOS, G. de (1985): "Estratigrafía de la Edad del Bronce en el Monte Berrueco (Medina Sidonia, Cádiz)”, Noticiario Arqueológico Hispánico 24: 7-90.

FERNÁNDEZ GÓMEZ, F. y ALONSO, J. (1985): "Un fondo de cabaña campaniforme en la Universidad Laboral de Sevilla", Noticiario Arqueológico Hispánico 22: 7-26.

FERNÁNDEZ GÓMEZ, F. y OLIVA, D. (1980): "Los ídolos calcolíticos del Cerro de la Cabeza (Valencina de la Concepción, Sevilla)", Madrider Mitteilungen 21: 20-44.

- (1985): "Excavaciones en el yacimiento Calcolítico de Valencina de la Concepción (Sevilla). El corte C (“La Perrera")", Noticiario Arqueológico Hispánico 25: 7-131.

FERNÁNDEZ GÓMEZ, F. y RUIZ MATA, D. (1978): "El tholos del Cerro de la Cabeza, en Valencina de la Concepción (Sevilla)", Trabajos de Prehistoria 35: 193-224.

FERRER, J.E. y FERNÁNDEZ RUIZ, J. (1988): "Avance al estudio de la industria en sílex de la Cueva de las Palomas (Teba, Málaga)", Mainake 10: 5-39.

FERRER, J.E.; FERNÁNDEZ RUIZ, J. y MARQUÉS, I. (1987): "Excavaciones en la necrópolis campaniforme de el Tardón (Antequera, Málaga), 1985", Anuario Arqueológico de Andalucía 1985. III. Actividades de Urgencia, Consejería de Cultura de la Junta de Andalucía. Sevilla: 240-243. 
FERRER, J.E. y MARQUES, I. (1978): “Avance de las campañas arqueológicas realizadas en la "Cueva de las Palomas", Teba (Málaga)”, Baética 1: 195-206.

FORTEA, J. y MARTÍ, B. (1984-85): "Consideraciones sobre los inicios del Neolítico en el Mediterráneo español”, Zephyrus 37-38: 167-199.

GILES, F.; MATA, E.; BENÍTEZ, R.; GONZÁLEZTORAYA, B. y MOLINA CARRIÓN, M.I. (1993-94): "Fechas de radiocarbono 14 para la Prehistoria y Protohistoria de la provincia de Cádiz", Boletín del Museo de Cádiz 6: 43-52.

GILMAN, A. (1984/1992): “The Iberian Peninsula, 6000-1500 B.C.”. En R.W. Ehrich (ed.) “'Chronologies in Old World Archaeology", University of Chicago Press. Chicago: 295-301.

GONZÁLEZ-GÓMEZ, C. (1992): "University of Granada radiocarbon dates VI", Radiocarbon 34/1: 133-139.

GONZÁLEZ-GÓMEZ, C.; LÓPEZ GONZÁLEZ, J.D. y DOMINGO, M. (1982): “University de Granada. Radiocarbon dates I", Radiocarbon 24/2: 217-221.

GONZÁLEZ-GÓMEZ, C.; SÁNCHEZ SÁNCHEZ, M.P. y DOMINGO, M. (1986): “Antigüedades de muestras arqueológicas determinadas por el laboratorio de datación por carbono-14 de la Universidad de Granada", Revista de Arqueología 65: 5-12.

GONZÁLEZ-GÓMEZ, C.; SÁNCHEZ SÁNCHEZ, M.P. y VILLAFRANCA, E. (1986): “University of Granada. Radiocarbon dates III", Radiocarbon 28/3: 1200-1205.

- (1987): "University of Granada. Radiocarbon dates IV", Radiocarbon 29/3: 381-388.

GONZÁLEZ QUINTERO, P. (1990): La cerámica de la Cueva del Toro y su relación con el Neolítico malagueño, Tesis Doctoral (microfichas), Universidad de La Laguna, La Laguna.

HEDGES, R.E.M.; HOUSLEY, R.A., BRONK, C.R. y KLINKEN, G.J. van (1995): "Radiocarbon dates from the Oxford AMS system: archaeometry datelist 19", Archaeometry 37/1: 195-214.

HOPF, M. y PELLICER, M. (1970): "Neolitischhe Getreidefunde in der Höhle von Nerja", Madrider Mitteilungen 11: 18-34.

KUNST, M. (1992): Zur Neolithisierung der Iberischen Halbinsel: Hindergrunde eines ungelosten Forschungsproblems. Breisach.

LÓPEZ PALOMO, L.A. (1993): Calcolítico y Edad de Bronce al sur de Córdoba. Estratigrafía en Monturque, Caja de Ahorros de Córdoba. Córdoba.

LULL, V.; GONZÁLEZMARCÉN, P. y RISCH, R. (1992): Arqueología de Europa, 2250-1200 A.C. Una introducción a la "edad del bronce", Síntesis. Madrid.

MARTÍN DE LA CRUZ, J.C. (1978-79): "Montoro. Un nuevo yacimiento arqueológico en el Guadalquivir". Cuadernos de Prehistoria y Arqueología de la Universidad Autónoma de Madrid 5-6: 105-141.

(1985): Papa Uvas I. Aljaraque, Huelva. Campañas de 1976 a 1979, Excavaciones Arqueológicas en España 136. Madrid.

(1986a): Papa Uvas II. Aljaraque, Huelva. Campañas de 1980 a 1983, Excavaciones Arqueológicas en España 149. Madrid.

(1986b): “Aproximación a la secuencia de hábitat en Papa Uvas (Aljaraque, Huelva)”, Homenaje a Luis Siret (1934-1984), Junta de Andalucía. Sevilla: 227-242.

(1987a): El Llanete de los Moros. Montoro, Córdoba, Excavaciones Arqueológicas en España 151.

Madrid.

(1987b): "La campaña de 1985 en el Llanete de los Moros-Palomarejo (Montoro, Córdoba)". Anuario Arqueológico de Andalucía 1985. II. Actividades Sistemáticas, Consejería de Cultura de la Junta de Andalucía. Sevilla: 313-318. 
(1987c): "Memoria de los trabajos realizados en el yacimiento de Papa Uvas (Aljaraque, Huelva)". Anuario Arqueológico de Andalucía 1986. II. Actividades Sistemáticas, Consejería de Cultura de la Junta de Andalucía. Sevilla: 311-316.

- (1989): "El Bronce en el valle medio del Guadalquivir”. En Mª.E. Aubet (ed.) “Tartessos. Arqueología Protohistórica del Bajo Guadalquivir", Ausa. Sabadell-Barcelona: 121-143.

(1993): "Papa Uvas (4). Génesis y desarrollo de la Edad del Bronce en la Cuenca Media del Guadalquivir: piedemonte y campiña hasta la confluencia del río Guadajoz", Investigaciones Arqueológicas en Andalucía 1985-1992. Proyectos, Consejería de Cultura y Medio Ambiente de la Junta de Andalucía. Huelva: 441-460. MARTÍN DE LA CRUZ, J.C. y BAQUEDANO, I. (1987): “Cerámicas inéditas del Bronce Final”, Revista de Arqueología 72: 50-56.

MARTÍN DE LA CRUZ, J.C.; CONSUEGRA, S. y MONTES, M.A. (1990): "Excavación de urgencia en el Llanete de los Moros (Montoro, Córdoba)", Anuario Arqueológico de Andalucía 1987. III. Actividades de Urgencia, Consejería de Cultura de la Junta de Andalucía. Sevilla: 165-172.

MARTÍN DE LA CRUZ, J.C.; GÓMEZ, M.J. y CONSUEGRA, S. (1990): "Informe sobre los trabajos realizados en Papa Uvas durante la campaña de 1987. (Aljaraque, Huelva)", Anuario Arqueológico de Andalucía 1987. II. Actividades Sistemáticas, Consejería de Cultura de la Junta de Andalucía. Sevilla: 246-251.

MARTÍN DE LA CRUZ, J.C.; GÓMEZ, M.J.; MONTES, A.; BAQUEDANO, M.I. y CONSUEGRA, S. (1987): "El Llanete de los Moros. Palomarejo". En J.C. Martín de la Cruz (ed.) “El Llanete de los Moros. Montoro, Córdoba", Excavaciones Arqueológicas en España 151. Madrid: 39-209.

MARTÍN DE LA CRUZ, J.C. y MONTES, A. (1986): "Avance del estudio sobre ẹl horizonte Cogotas I en la Cuenca Media del Guadalquivir”, Homenaje a Luis Siret (1934-1984), Junta de Andalucía. Sevilla: 488-496.

MARTÍN DE LA CRUZ, J.C. y PERLINES, M. (1993): “La cerámica a torno de los contextos culturales de finales del II milenio A.C. en Andalucía", I Congresso de Arqueología Peninsular (Porto, 1993). Actas. II. Trabalhos de Antropologia e Etnologia 33/3-4. Porto: 335-349.

MARTÍN-SOCAS, D.; CAMALICH, M.D.; BUXÓ, R.; GONZÁLEZ QUINTERO, P.; MARTÍNEZ, G.; MEDEROS, A.; MENESES, M.D.; PAZ, J. de; RODRÍGUEZ ARIZA, Ma.O.; WATSON, J. et alii. (1989): "Resultados de la campaña de Excavaciones y Prospección Arqueológica en la cueva de El Toro y Sierra del Torcal”, II Jornadas de Arqueología Andaluza (Antequera-Málaga, 1989). Málaga: 1-5.

MEDEROS, A. (1993): Los Estados Incipientes del sureste de la Península Ibérica. Repercusiones en las cuencas de los rios Aguas, Antas y Almanzora. Almería (4500-1300 a.C./5300-1600 A.C.), Tesis Doctoral inédita en prensa, Universidad de La Laguna. La Laguna.

- (e.p.): "La cronología absoluta de la prehistoria reciente del sureste de la Península Ibérica", Pyrenae. MENESES, M.D. (1991): Propuesta metodológica para el análisis de la industria osea: el Neolítico en Andalucía, La Cueva del Toro, Tesis Doctoral (microfichas), Universidad de La Laguna. La Laguna. MOLINA, F. (1978): "Definición y sistematización del Bronce Tardío y Final en el Sudeste de la Península Ibérica”, Cuadernos de Prehistoria de la Universidad de Granada 3: 159-232.

MUÑOZ, A.M. (1972): “Análisis de carbono 14 sobre muestras recogidas por el Instituto de Arqueología de la Universidad de Barcelona", Pyrenae 8: 147-150.

-(1974): "El neolítico de la Cueva de los Murciélagos de Zuheros", Trabajos de Prehistoria 31: 293-294. MURILLO, J.F. (1995): La Cultura Tartésica en el Guadalquivir Medio, Universidad de Córdoba. Córdoba. NIEMEYER, H.G. y SCHUBART, H. (1975): Trayamar. Die phönizischen Kammergräber und die Niederlassung an der Algarrobo-Mündung, Madrider Beiträge 4. Mainz.

OBERMAIER, H. (1919): El dolmen de Matarrubilla (Sevilla), Memorias de la Comisión de Investigaciones Paleontológicas y Prehistóricas 76. Madrid. 
PELLICER, M. (1963): Estratigrafia prehistórica de la Cueva de Nerja. Excavaciones Arqueológicas en España 16. Madrid.

(1987): "El Neolítico de la Cueva de Nerja (Málaga)". En J. Guilaine (ed.) "Premières communautés Paysannes en Mediterranée occidentale" (Montpellier, 1983), C.N.R.S. Paris: 639-643.

— y ACOSTA, P. (1982): "El Neolítico antiguo en Andalucía occidental", Le Néolithique ancien Méditerranéen (Montpellier, 1981), Archeologie en Languedoc 7. Lattes: 49-60

_ (1986): "Neolítico y Calcolítico de la Cueva de Nerja". En J.F. Jordá Pardo (ed.) "La Prehistoria de la Cueva de Nerja (Málaga)", Patronato de la Cueva de Nerja. Málaga.

PELLICER, M. y HURTADO, V. (1980): El poblado metalúrgico de Chinflón (Zalamea la Real, Huelva), Publicaciones del Departamento de Prehistoria y Arqueología, Universidad de Sevilla. Sevilla.

RODRÍGUEZ ARIZA, M.O. (1992): Las relaciones hombre-vegetación en el Sureste de la península lbérica durante las Edades del Cobre y Bronce a partir del análisis antracológico, Tesis Doctorales de la Universidad de Granada (microfichas). Granada.

ROTHENBERG, B. y BLANCO, A. (1980): “Ancient copper mining and smelting at Chinflón (Huelva, S.W. Spain)”. En P.T. Craddock (ed.) "Scientific Studies in Early Mining and Metallurgy”, British Museum Occasional Paper 20. London: 41-55.

SCHUBART, H. (1977): "Morro de Mezquitilla. Vorbericht über die Grabungskampagne1976 auf dem Siedlungshügel an der Algarrobo-Mündung", Madrider Mitteilungen 18: 33-

__ (1979): "Morro de Mezquitilla. Informe preliminar sobre la campaña de excavaciones 1976", Noticiario Arqueológico Hispánico 6: 175-218.

_ (1982): "Morro de Mezquitilla. Vorbericht über die Grabungskampagne 1982 auf dem Siedlungshügel an der Algarrobo-Mündung", Madrider Mitteilungen 23: 33-45.

- (1983): "Morro de Mezquitilla. Vorbericht über die Grabungskampagne 1982 auf dem Siedlungshügel an der Algarrobo-Mündung", Madrider Mitteilungen 24: 104-131.

(1985): "Morro de Mezquitilla. Informe preliminar sobre la campaña de excavaciones realizada en el asentamiento fenicio cerca de la desembocadura del río Algarrobo", Noticiario Arqueológico Hispánico 23: 141-174.

- y NIEMEYER, H.G. (1976): Trayamar. Los hipogeos fenicios y el asentamiento en la desembocadura del río Algarrobo, Excavaciones Arqueológicas en España 90. Madrid.

STUIVER, M. y REIMER, P.J. (1993): "Extended ${ }^{14} \mathrm{C}$ Data Base and Revised Calib $3.0{ }^{14} \mathrm{C}$ Age Calibration Program", Radiocarbon 35/1: 215-230.

VICENT, A.M. y MUÑOZ, A.M.(1973): Segunda campaña de excavaciones, la cueva de los Murciélagos, Zuheros (Córdoba), Excavaciones Arqueológicas en España 77. Madrid.

ZILHÃO, J. (1993): "The Spread of Agro-Pastoral Economies across Mediterranean Europe: a View from the Far West", Journal of Mediterranean Archaeology 6/1: 5-63. 